\title{
Seismic Behavior Factors of RC Staggered Wall Buildings
}

\author{
Jinkoo Kim*, Yong Jun, and Hyunkoo Kang
}

\author{
(Received September 21, 2015, Accepted April 9, 2016, Published online April 27, 2016)
}

\begin{abstract}
In this study seismic performance of reinforced concrete staggered wall system structures were investigated and their behavior factors such as overstrength factors, ductility factors, and the response modification factors were evaluated from the overstrength and ductility factors. To this end, 5, 9, 15, and 25-story staggered wall system (SWS) structures were designed and were analyzed by nonlinear static and dynamic analyses to obtain their nonlinear force-displacement relationships. The response modification factors were computed based on the overstrength and the ductility capacities obtained from capacity envelopes. The analysis results showed that the 5- and 9-story SWS structures failed due to yielding of columns and walls located in the lower stories, whereas in the 15- and 25-story structures plastic hinges were more widely distributed throughout the stories. The computed response modification factors increased as the number of stories decreased, and the mean value turned out to be larger than the value specified in the design code.
\end{abstract}

Keywords: staggered wall systems, seismic design, overstrength factors, ductility factors, response factors.

\section{Introduction}

Reinforce concrete (RC) shear walls are key elements to resist both gravity and lateral loads in building structures, and the seismic performance and analysis modeling of RC shear wall structures have been widely investigated by many researchers (e.g., Wallace 2012). Recently an alternative building structure system, a staggered wall system, has drawn attention due mainly to its capability to provide wider open space. The staggered-wall system consists of a series of storey-high RC walls spanning the total width between two rows of exterior columns and arranged in a staggered pattern on adjacent column lines. With the columns only on the exterior of the building, a full width of column-free area can be created. Compared with traditional shear wall structures, the structures with vertical walls placed at alternate levels have advantage for their enhanced spatial flexibility. Currently Korean government provides various incentives for apartment buildings designed with increased spatial flexibility. In this regard the apartment buildings with vertical walls placed at alternate levels have advantage for their enhanced spatial flexibility. Such a structural system has already been widely applied in steel residential buildings, which is typically called a staggered truss system.

The system was first proposed by Fintel (1968), who found out that the staggered wall systems are very competitive with the conventional form of construction and are more

Department of Civil and Architectural Engineering, Sungkyunkwan University, Suwon, Korea. *Corresponding Author; E-mail: jkim12@skku.edu Copyright $($ The Author(s) 2016. This article is published with open access at Springerlink.com economical. Mee et al. (1975) carried out shaking table tests of $1 / 15$ scaled models for the staggered wall systems and found that the consistent mass analysis gave reasonable estimation of dynamic behavior of the system. Kim and Jun (2011) evaluated the seismic performance of partially staggered wall apartment buildings using non-linear static and dynamic analysis, and compared the results with those of conventional shear wall apartment buildings. Lee and Kim (2013) investigated the seismic performance of six and 12-story staggered wall structures with a middle corridor based on the FEMA P695 procedure. It was found that the collapse margin ratios of the model structures obtained from incremental dynamic analyses turned out to be larger than the limit states specified in the FEMA P695. Kim and Han (2013) investigated the sensitivity of design variables to the seismic response of staggered wall structures. It was observed that when the earthquake intensity is relatively small, the yield stress of rebars and the concrete strength in the link beams are important factors as well as inherent damping ratio. As the intensity of seismic load increased, the strength of columns became another important factor. Lee and Kim (2013) derived empirical formulas for fundamental natural period of reinforced concrete staggered wall structures. They found that the natural periods of the staggered wall structures are similar to those of the shear wall structures having the same overall configuration.

The staggered wall systems, however, have not been considered as one of the basic seismic-force-resisting systems in most design codes due mainly to the vertical discontinuity of the main structural elements. ASCE 7 (2010) requires that lateral systems that are not listed as the basic seismic-forceresisting systems shall be permitted if analytical and test data are submitted to demonstrate the lateral force resistance and energy dissipation capacity. The American Institute of Steel 
Construction (AISC) Design Guide 14 (AISC 2002) recommends the response modification factor of 3.0 for seismic design of staggered truss system buildings; however none is specified for reinforced concrete staggered wall systems.

Seismic behavior factors including the response modification factors are essential for seismic design of structures. The factors are provided for typical structure systems in most design codes. However for non-typical structures the determination of the behavior factors is an important issue (e.g. Tomaževič and Weiss 2010, Skalomenos et al. 2015). In this study the behavior factors such as overstrength factors, ductility factors, and the response modification factors of reinforced concrete staggered wall system (SWS) structures were evaluated following the procedure recommended in the ATC 19 (1995). To this end, 5, 9, 15, and 25-story SWS structural models were designed and were analyzed by nonlinear static and dynamic analyses to obtain their force-displacement relationship up to failure. The response modification factors were computed based on the overstrength and the ductility capacities obtained from the capacity envelopes.

\section{Analysis Model Structures}

\subsection{Configuration of Staggered Wall System Analysis Models}

To evaluate seismic performance and behavior factors of reinforced concrete staggered wall structures, the rectangular plan staggered wall systems with $5,9,15$, and 25 stories and wall length of 6 and $9 \mathrm{~m}$ were designed. Figure 1 shows the structural plan and the three-dimensional view of the 5-story model structure with $9 \mathrm{~m}$ parallel staggered walls. In the model structures, the story-high RC walls that span the width of the building are located in a staggered pattern. The staggered arrangement of the floor-deep walls placed at alternate levels on adjacent column lines allows an interior floor space of twice the column spacing to be available for freedom of floor arrangements. The floor system spans from the top of one staggered wall to the bottom of the adjacent wall serving as a diaphragm. The horizontal load is transferred to staggered walls below through diaphragm action of floor slabs. In this study the staggered walls were designed as story-high deep beams. The combined system of floor diaphragm and staggered wall acts like H-shaped deep beam which resists the applied load efficiently. With RC walls located at alternate floors, flexibility in spatial planning can be achieved compared with conventional wall-type structures with vertically continuous shear walls.

Columns and beams are located along the longitudinal perimeter of the structures providing a full width of columnfree area within the structure. Along the longitudinal direction, the column-beam combination resists lateral load as a moment resisting frame. Along the transverse direction, the columns are expected to have minimum bending moments because of the cantilever action of the double-frame deformation configuration as illustrated in Fig. 2. The naming

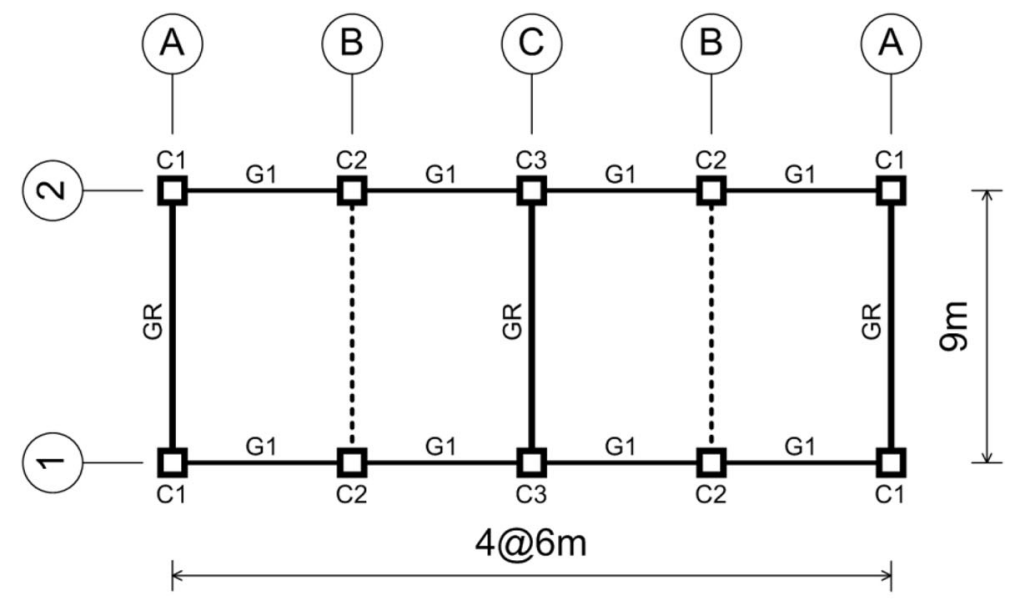

(a)

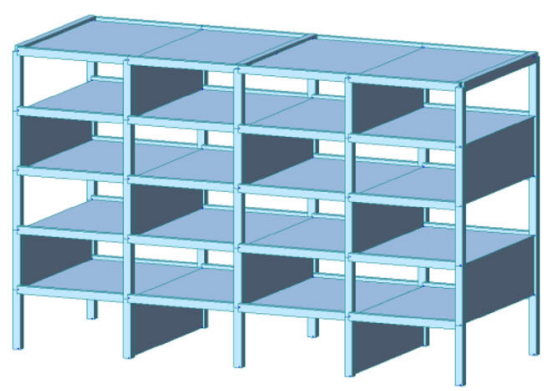

(b)

Fig. 1 Staggered wall analysis model structure. a Structural plan. b Three-dimensional view. 

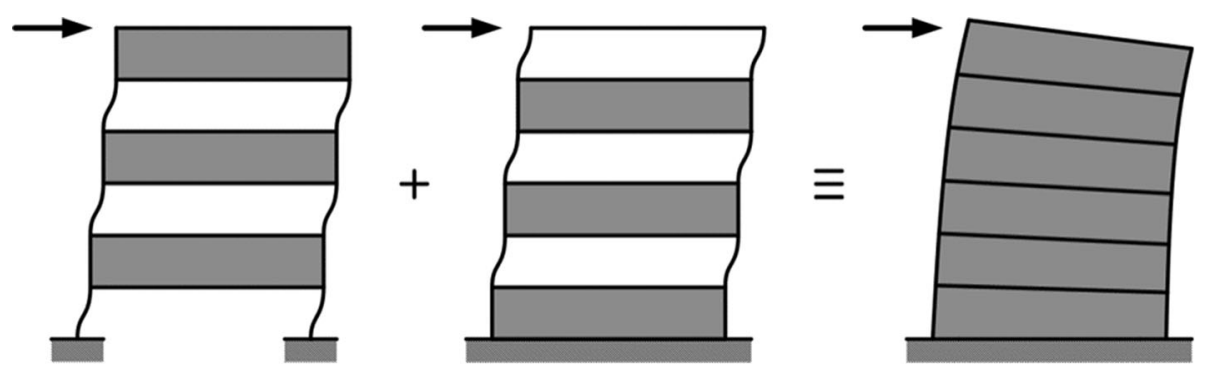

Fig. 2 Behavior of a staggered wall system subjected to lateral loads.

Table 1 Naming plan for analysis model structures.

\begin{tabular}{|c|c|c|c|}
\hline Length of wall (m) & Seismic region & Number of story & Name \\
\hline \multirow[t]{8}{*}{6} & \multirow[t]{4}{*}{ Low seismic region } & 5 & $5 \mathrm{~F} \_6 \mathrm{~m}$ low \\
\hline & & 9 & 9F_6 m low \\
\hline & & 15 & 15F_6 m low \\
\hline & & 25 & 25F_6 m low \\
\hline & \multirow[t]{4}{*}{ Medium seismic region } & 5 & 5F_6 m medium \\
\hline & & 9 & 9F_6 m medium \\
\hline & & 15 & 15F_6 m medium \\
\hline & & 25 & 25F_6 m medium \\
\hline \multirow[t]{8}{*}{9} & \multirow[t]{4}{*}{ Low seismic region } & 5 & 5F_9 m low \\
\hline & & 9 & 9F_9 m low \\
\hline & & 15 & 15F_9 m low \\
\hline & & 25 & 25F_9 m low \\
\hline & \multirow[t]{4}{*}{ Medium seismic region } & 5 & 5F_9 $\mathrm{m}$ medium \\
\hline & & 9 & 9F_9 $\mathrm{m}$ medium \\
\hline & & 15 & 15F_9 m medium \\
\hline & & 25 & 25F_9 $\mathrm{m}$ medium \\
\hline
\end{tabular}

plan for the analysis model structures depending on the design variables such as length of staggered walls, design seismic load level, and number of story are presented in Table 1.

\subsection{Structural Design of Analysis Model Structures}

The model structures were designed per the ACI 318-14 (ACI 2014) using the design loads specified in the ASCE 7-13 (2010). The dead load was estimated to be $4.71 \mathrm{kN} / \mathrm{m}^{2}$ including the weight of the structure itself and immovable fixtures, and live loads of $1.92 \mathrm{kN} / \mathrm{m}^{2}$ was used assuming that the structure was used as residential buildings. The staggered wall structures, as well as the staggered truss structures, have not been included in seismic load resisting systems due mainly to the fact that the lateral load resisting system, the staggered walls, is not vertically continuous. In addition, as the staggered walls act like story-high deep beams, the structures are similar to typical weak column-strong beam systems. Therefore in this study response modification factor of 3.0 was used in the structural design of the staggered wall systems, which is generally used for the structures to be designed without consideration of seismic detailing. Table 2 shows the seismic coefficients used for evaluation of design seismic load following the ASCE 7-13 specification, where the parameters $S_{\mathrm{s}}$ and $\mathrm{S}_{1}$ represent the maximum considered earthquake (MCE) spectral response acceleration parameters at short period and at $1 \mathrm{~s}$ period, respectively, and the parameters $S_{D S}$ and $S_{D 1}$ represent the design spectral response acceleration at short and at a period of $1 \mathrm{~s}$, respectively. To consider the effect of design seismic load levels, the model structures were designed with two different levels of seismic loads corresponding to low and medium seismic regions. The design seismic loads for the structures located in the low and the medium seismic regions were determined based on the assumption that the structures were located in the class B site (rock) and C site (very dense soil or soft rock), respectively. The design spectrum for low seismic region was constructed using the design spectral response acceleration parameters, $\mathrm{S}_{\mathrm{DS}}$ and $\mathrm{S}_{\mathrm{D} 1}$, of 0.31 and 0.13 , respectively. The design spectrum for medium seismic region was constructed using 
Table 2 Seismic coefficients used for evaluation of design seismic load.

\begin{tabular}{|c|c|c|}
\hline Seismic load level & Low & Medium \\
\hline \multicolumn{3}{|c|}{ Maximum considered earthquake } \\
\hline $\mathrm{S}_{\mathrm{S}}$ & 0.46 & 0.80 \\
\hline $\mathrm{S}_{1}$ & 0.19 & 0.30 \\
\hline Site class & B & $\mathrm{C}$ \\
\hline \multicolumn{3}{|c|}{ Design earthquake } \\
\hline $\mathrm{S}_{\mathrm{DS}}$ & 0.31 & 0.57 \\
\hline $\mathrm{S}_{\mathrm{D} 1}$ & 0.13 & 0.20 \\
\hline $\mathrm{S}_{\mathrm{a}}(\mathrm{T}=0)$ & 0.12 & 0.23 \\
\hline R-factor & \multicolumn{2}{|c|}{3} \\
\hline
\end{tabular}

the acceleration parameters of 0.57 and 0.20 , respectively. At zero natural period $(\mathrm{T}=0)$, the spectral response accelerations for the Low and the Medium earthquakes are 0.12 and 0.23 , respectively. The ultimate strength of concrete is $24 \mathrm{MPa}$ and the tensile yield stress of re-bars is $400 \mathrm{MPa}$. The thickness of the staggered walls is $20 \mathrm{~cm}$ throughout the stories. The thickness of the floor slabs is $21 \mathrm{~cm}$ which is the minimum thickness required for wall-type apartment buildings in Korea to prevent transmission of excessive noise and vibration through the floors. The thickness of the staggered walls is $20 \mathrm{~cm}$ throughout the stories. The rebar placements in the columns and staggered walls are presented in Table 3. The reinforcements of the columns followed the seismic detailing of ordinary moment resisting frames specified in the ACI 318 (2014). The staggered walls were designed as deep beams, for which only minimum reinforcement of D10@400 was needed both horizontal and vertical directions due to their large depth. Table 4 shows the fundamental natural periods of the analysis model structures along the transverse direction where the staggered walls are located, where it can be observed that the natural periods of the structures designed for medium seismic load are slightly shorter than those of the structures designed for low seismic load.

\subsection{Modeling for Analysis}

The seismic performances of the model structures were evaluated using the nonlinear analysis program CANNY (Li 2004) which utilizes fiber model for modeling elements. Fiber model has been proven to be effective in nonlinear analysis of structures by various researchers (e.g. Sfakianakis 2002; Calabrese et al. 2010; Li and Hatzigeorgiou 2012; Li et al. 2013). In this study both the material and the geometric nonlinearities were considered in the analysis. The geometric nonlinearity was considered by member level and the frame level p-delta effect. The material nonlinear behavior of the concrete was modeled using the work of Kent and Park (1971) as shown in Fig. 3 where the ultimate strength $f_{c}^{\prime}=24 \mathrm{MPa}$ and $\varepsilon_{50 u}=$ the strains corresponding to the stress equal to $50 \%$ of the maximum concrete strength for unconfined concrete. The reinforcing steel was modeled by bi-linear lines with yield stress of $400 \mathrm{MPa}$ and $2 \%$ of post-yield stiffness.
$E$ is the elastic modulus of steel rebars. The expected ultimate strengths of the concrete and steel were taken to be 1.5 and 1.25 times the nominal strengths based on the recommendation of the FEMA-356 (FEMA 2000). As the model structures were designed without considering seismic detailing, the confinement effect of concrete was neglected in the stressstrain relationship. The columns and walls were modeled by the multi-axial spring model with fiber elements as shown in Fig. 4. The axial/bending deformation was simulated by elongation or contraction of each fiber element. The in-plane shear force is resisted by the spring $W$ and the out-of-plane shear is resisted by the springs $C 1$ and $C 2$, respectively. The symbols $I_{1}$ and $A_{s 1}$ denote the moment of inertia and rebar cross-sectional area of the element $C 1$, and $I_{2}$ and $A_{s 2}$ denote the moment of inertia and rebar cross-sectional area of the element $C 2$, respectively. The symbols $I$ and $A_{s}$ denote the moment of inertia and rebar cross-sectional area of the element $W$. The symbols $d$ and $\theta$ denote the displacement and the rotation at a joint, respectively. The hysteretic behavior of the shear springs was idealized by the origin-oriented model based on the tri-linear hysteresis curve as described in Fig. 5, which can consider the decrease in gradient of loading as the loading cycle and the deformation increase. It is assumed that the cross section of the shear walls remains plane when an inplane wall deformation occurs. Following the plane section remain plane assumption, strain of the fiber element in the cross section is proportional to the distance from the neutral axis. The stress of each slice is calculated using the stressstrain relation from the strain of each fiber slice, and the bending moment is calculated by summing the moments to the center of the cross section. Figure 6 shows the modified Clough model used to simulate the bending deformation of the elements (Clough and Johnston 1966). The model is composed of bi-linear lines and may represent the degradation of stiffness after yielding. Even though the simplified originoriented hysteresis model may not be quite accurate for predicting shear response of the wall element, especially under high shear stresses, it was employed in this study for the following reasons: (i) the staggered walls act more like deep beams rather than shear walls, and (ii) for design level earthquakes, inelastic deformations are concentrated mostly 
Table 3 Rebar details in the analysis model structure.

(a) Beams

\begin{tabular}{|c|c|c|c|c|c|c|c|c|c|c|}
\hline \multicolumn{11}{|c|}{ Bar-placement detail (beam) } \\
\hline & \multirow{3}{*}{\multicolumn{2}{|c|}{ Type }} & \multicolumn{4}{|c|}{ Low seismic region } & \multicolumn{4}{|c|}{ Medium seismic region } \\
\hline & & & \multicolumn{2}{|c|}{ Dimension $(\mathrm{mm})$} & \multicolumn{2}{|c|}{ Rebar } & \multicolumn{2}{|c|}{ Dimension $(\mathrm{mm})$} & \multicolumn{2}{|c|}{ Rebar } \\
\hline & & & $\mathrm{H}$ & $\mathrm{B}$ & Upper & Lower & $\mathrm{H}$ & $\mathrm{B}$ & Upper & Lower \\
\hline \multirow[t]{3}{*}{$5 \mathrm{~F}$} & \multirow[t]{2}{*}{ G1 } & $1-3 \mathrm{~F}$ & 350 & 220 & 4-D22 & $2-\mathrm{D} 22$ & 400 & 250 & $5-\mathrm{D} 25$ & $3-\mathrm{D} 25$ \\
\hline & & $4-5 \mathrm{~F}$ & 350 & 220 & 4-D19 & 2-D19 & 350 & 220 & $4-\mathrm{D} 22$ & $2-\mathrm{D} 22$ \\
\hline & GR & $5 \mathrm{~F}$ & 400 & 250 & 3-D19 & 3-D19 & 350 & 220 & 4-D19 & 3-D19 \\
\hline \multirow[t]{4}{*}{$9 \mathrm{~F}$} & \multirow[t]{3}{*}{ G1 } & $1-3 \mathrm{~F}$ & 350 & 220 & 4-D22 & $2-\mathrm{D} 22$ & 400 & 250 & $5-\mathrm{D} 25$ & $4-\mathrm{D} 25$ \\
\hline & & $4-6 \mathrm{~F}$ & 350 & 220 & $4-\mathrm{D} 22$ & 2-D22 & 400 & 250 & $5-\mathrm{D} 25$ & $4-\mathrm{D} 25$ \\
\hline & & $7-9 \mathrm{~F}$ & 350 & 220 & 4-D19 & 2-D19 & 400 & 250 & $5-\mathrm{D} 22$ & $3-\mathrm{D} 22$ \\
\hline & GR & $9 \mathrm{~F}$ & 400 & 250 & $2-\mathrm{D} 22$ & $3-\mathrm{D} 22$ & 350 & 220 & 4-D19 & 3-D19 \\
\hline \multirow[t]{6}{*}{$15 \mathrm{~F}$} & \multirow[t]{5}{*}{ G1 } & $1-3 \mathrm{~F}$ & 350 & 220 & 4-D25 & 2-D25 & 450 & 300 & 6-D25 & $5-\mathrm{D} 25$ \\
\hline & & $4-6 \mathrm{~F}$ & 350 & 220 & $4-\mathrm{D} 25$ & $2-\mathrm{D} 25$ & 450 & 300 & $6-\mathrm{D} 25$ & $5-\mathrm{D} 25$ \\
\hline & & $7-9 \mathrm{~F}$ & 350 & 220 & $5-\mathrm{D} 22$ & $2-\mathrm{D} 22$ & 450 & 300 & $5-\mathrm{D} 25$ & 4-D25 \\
\hline & & $10-12 \mathrm{~F}$ & 350 & 220 & 5-D19 & 2-D19 & 400 & 250 & $5-\mathrm{D} 25$ & $3-\mathrm{D} 25$ \\
\hline & & $13-15 \mathrm{~F}$ & 350 & 220 & 4-D19 & 2-D19 & 400 & 250 & 5-D22 & $3-\mathrm{D} 22$ \\
\hline & GR & $15 \mathrm{~F}$ & 400 & 250 & $2-\mathrm{D} 22$ & $3-\mathrm{D} 22$ & 350 & 220 & 4-D19 & 3-D19 \\
\hline \multirow[t]{9}{*}{$25 \mathrm{~F}$} & \multirow[t]{8}{*}{ G1 } & $1-3 \mathrm{~F}$ & 400 & 250 & $4-\mathrm{D} 25$ & $2-\mathrm{D} 25$ & 500 & 320 & $6-\mathrm{D} 25$ & $5-\mathrm{D} 25$ \\
\hline & & $4-6 \mathrm{~F}$ & 400 & 250 & 4-D25 & 2-D25 & 500 & 320 & 6-D25 & $5-\mathrm{D} 25$ \\
\hline & & $7-9 \mathrm{~F}$ & 400 & 250 & $4-\mathrm{D} 25$ & $2-\mathrm{D} 25$ & 500 & 320 & 7-D25 & $5-\mathrm{D} 25$ \\
\hline & & $10-12 \mathrm{~F}$ & 400 & 250 & $4-\mathrm{D} 25$ & $2-\mathrm{D} 25$ & 450 & 300 & $6-\mathrm{D} 25$ & $5-\mathrm{D} 25$ \\
\hline & & $13-15 \mathrm{~F}$ & 400 & 250 & $4-\mathrm{D} 25$ & $2-\mathrm{D} 25$ & 450 & 300 & $6-\mathrm{D} 25$ & $5-\mathrm{D} 25$ \\
\hline & & $16-18 \mathrm{~F}$ & 350 & 220 & 4-D22 & 2-D22 & 400 & 250 & $6-\mathrm{D} 25$ & 4-D25 \\
\hline & & $19-21 \mathrm{~F}$ & 350 & 220 & 5-D19 & 2-D19 & 400 & 250 & $5-\mathrm{D} 25$ & $3-\mathrm{D} 25$ \\
\hline & & $22-25 \mathrm{~F}$ & 350 & 220 & 4-D19 & 2-D19 & 350 & 220 & $4-\mathrm{D} 25$ & $2-\mathrm{D} 25$ \\
\hline & GR & $25 \mathrm{~F}$ & 400 & 250 & 3-D19 & 3-D19 & 350 & 220 & 4-D19 & 3-D19 \\
\hline
\end{tabular}

(b) Columns

Bar-placement detail (column)

\begin{tabular}{|c|c|c|c|c|c|c|c|c|c|c|c|c|c|}
\hline & \multirow[t]{3}{*}{ Type } & \multicolumn{6}{|c|}{ Low seismic region } & \multicolumn{6}{|c|}{ Medium seismic region } \\
\hline & & \multicolumn{2}{|c|}{$\mathrm{C} 1$} & \multicolumn{2}{|c|}{$\mathrm{C} 2$} & \multicolumn{2}{|c|}{ C3 } & \multicolumn{2}{|c|}{$\mathrm{C} 1$} & \multicolumn{2}{|c|}{$\mathrm{C} 2$} & \multicolumn{2}{|c|}{$\mathrm{C} 3$} \\
\hline & & $\mathrm{BH}$ & Rebar & $\mathrm{BH}$ & Rebar & $\mathrm{BH}$ & Rebar & $\mathrm{BH}$ & Rebar & $\mathrm{BH}$ & Rebar & $\mathrm{BH}$ & Rebar \\
\hline \multirow[t]{2}{*}{$5 \mathrm{~F}$} & $1-3 \mathrm{~F}$ & 400 & $8-\mathrm{D} 22$ & 600 & $16-\mathrm{D} 22$ & 400 & 12-D22 & 600 & $16-\mathrm{D} 22$ & 400 & $8-\mathrm{D} 22$ & 600 & 12-D22 \\
\hline & $4-5 \mathrm{~F}$ & 400 & $8-\mathrm{D} 22$ & 550 & 8 -D22 & 400 & 12-D22 & 550 & 8-D22 & 400 & $6-\mathrm{D} 22$ & 550 & 16-D22 \\
\hline \multirow[t]{3}{*}{$9 \mathrm{~F}$} & $1-3 \mathrm{~F}$ & 400 & $12-\mathrm{D} 22$ & 650 & 16-D22 & 500 & 16-D22 & 650 & 12-D25 & 500 & $12-\mathrm{D} 22$ & 650 & 16-D22 \\
\hline & $4-6 \mathrm{~F}$ & 400 & 6-D19 & 600 & 14-D19 & 450 & 8-D19 & 600 & 10-D22 & 450 & $6-\mathrm{D} 22$ & 600 & 10-D22 \\
\hline & $7-9 \mathrm{~F}$ & 400 & $8-\mathrm{D} 22$ & 550 & 6-D25 & 400 & 12-D22 & 550 & 6-D25 & 400 & 6-D19 & 550 & $8-\mathrm{D} 25$ \\
\hline \multirow[t]{5}{*}{$15 \mathrm{~F}$} & $1-3 \mathrm{~F}$ & 550 & $6-\mathrm{D} 25$ & 750 & 12-D25 & 600 & $8-\mathrm{D} 25$ & 650 & $12-\mathrm{D} 25$ & 600 & $12-\mathrm{D} 25$ & 750 & 16-D25 \\
\hline & $4-6 \mathrm{~F}$ & 500 & $6-\mathrm{D} 25$ & 700 & $10-\mathrm{D} 25$ & 550 & 6-D25 & 600 & 10-D22 & 550 & 16-D19 & 700 & $10-\mathrm{D} 25$ \\
\hline & $7-9 \mathrm{~F}$ & 450 & $4-\mathrm{D} 25$ & 650 & $10-\mathrm{D} 25$ & 550 & 6-D25 & 550 & 6-D25 & 500 & 16-D16 & 650 & 10-D25 \\
\hline & $10-12 \mathrm{~F}$ & 420 & $4-\mathrm{D} 25$ & 600 & $10-\mathrm{D} 22$ & 500 & 6-D25 & 500 & 6-D25 & 500 & 16-D16 & 600 & $8-\mathrm{D} 25$ \\
\hline & $13-15 \mathrm{~F}$ & 420 & $8-\mathrm{D} 25$ & 550 & 6-D25 & 500 & $8-\mathrm{D} 25$ & 500 & $6-\mathrm{D} 25$ & 450 & $4-\mathrm{D} 25$ & 550 & $6-\mathrm{D} 25$ \\
\hline
\end{tabular}


Table 3 continued

(b) Columns

Bar-placement detail (column)

\begin{tabular}{|c|c|c|c|c|c|c|c|c|c|c|c|c|c|}
\hline & \multirow[t]{3}{*}{ Type } & \multicolumn{6}{|c|}{ Low seismic region } & \multicolumn{6}{|c|}{ Medium seismic region } \\
\hline & & \multicolumn{2}{|c|}{$\mathrm{C} 1$} & \multicolumn{2}{|c|}{$\mathrm{C} 2$} & \multicolumn{2}{|c|}{$\mathrm{C} 3$} & \multicolumn{2}{|c|}{$\mathrm{C} 1$} & \multicolumn{2}{|c|}{$\mathrm{C} 2$} & \multicolumn{2}{|c|}{$\mathrm{C} 3$} \\
\hline & & $\mathrm{BH}$ & Rebar & $\mathrm{BH}$ & Rebar & $\mathrm{BH}$ & Rebar & $\mathrm{BH}$ & Rebar & $\mathrm{BH}$ & Rebar & $\mathrm{BH}$ & Rebar \\
\hline \multirow[t]{8}{*}{$25 \mathrm{~F}$} & $1-3 \mathrm{~F}$ & 700 & $10-\mathrm{D} 25$ & 750 & 20-D29 & 800 & $14-\mathrm{D} 25$ & 600 & $20-\mathrm{D} 25$ & 800 & $16-\mathrm{D} 25$ & 750 & $20-\mathrm{D} 29$ \\
\hline & $4-6 \mathrm{~F}$ & 650 & $10-\mathrm{D} 25$ & 700 & $20-\mathrm{D} 25$ & 750 & $12-\mathrm{D} 25$ & 550 & $12-\mathrm{D} 25$ & 750 & $16-\mathrm{D} 25$ & 700 & $18-\mathrm{D} 29$ \\
\hline & $7-9 \mathrm{~F}$ & 600 & $8-\mathrm{D} 25$ & 650 & 20-D25 & 700 & $10-\mathrm{D} 25$ & 500 & $10-\mathrm{D} 25$ & 700 & $10-\mathrm{D} 25$ & 650 & $16-\mathrm{D} 29$ \\
\hline & $10-12 \mathrm{~F}$ & 550 & $6-\mathrm{D} 25$ & 600 & 16-D25 & 650 & $10-\mathrm{D} 25$ & 450 & $10-\mathrm{D} 25$ & 650 & $10-\mathrm{D} 25$ & 600 & $16-\mathrm{D} 29$ \\
\hline & $13-15 \mathrm{~F}$ & 500 & $6-\mathrm{D} 25$ & 550 & $10-\mathrm{D} 25$ & 600 & $10-\mathrm{D} 25$ & 400 & 8-D25 & 600 & 10-D25 & 550 & $12-\mathrm{D} 29$ \\
\hline & $16-18 \mathrm{~F}$ & 450 & $4-\mathrm{D} 25$ & 500 & 10-D25 & 550 & 6-D25 & 400 & 8 -D25 & 550 & 6-D25 & 500 & 8-D29 \\
\hline & 19-21 F & 450 & $4-\mathrm{D} 25$ & 450 & 12-D25 & 500 & 6-D25 & 400 & 10-D25 & 500 & 6-D25 & 450 & 12-D29 \\
\hline & $22-25 \mathrm{~F}$ & 400 & $8-\mathrm{D} 25$ & 400 & $10-\mathrm{D} 25$ & 450 & $10-\mathrm{D} 25$ & 400 & 8-D25 & 450 & 4-D25 & 400 & $8-\mathrm{D} 29$ \\
\hline
\end{tabular}

Table 4 Fundamental natural periods of model structures along the transverse direction.

\begin{tabular}{|c|c|c|c|}
\hline Wall length $(\mathrm{m})$ & Seismic load level & Story & Period (s) \\
\hline \multirow[t]{8}{*}{6} & \multirow[t]{4}{*}{ Low } & 5 & 0.15 \\
\hline & & 9 & 0.43 \\
\hline & & 15 & 1.09 \\
\hline & & 25 & 2.37 \\
\hline & \multirow[t]{4}{*}{ Medium } & 5 & 0.14 \\
\hline & & 9 & 0.36 \\
\hline & & 15 & 0.88 \\
\hline & & 25 & 2.04 \\
\hline \multirow[t]{8}{*}{9} & \multirow[t]{4}{*}{ Low } & 5 & 0.13 \\
\hline & & 9 & 0.32 \\
\hline & & 15 & 0.69 \\
\hline & & 25 & 1.47 \\
\hline & \multirow[t]{4}{*}{ Medium } & 5 & 0.11 \\
\hline & & 9 & 0.26 \\
\hline & & 15 & 0.59 \\
\hline & & 25 & 1.36 \\
\hline
\end{tabular}

in columns and most staggered walls remain elastic. At the first yield point, $f_{e}$, the post-yield stiffness was set to be $16 \%$ of the initial stiffness, and after the final yield point, $f_{y}$, the stiffness was reduced to $0.1 \%$ of the initial stiffness. The slabs were considered as rigid diaphragm.

\section{Seismic Performance Evaluation}

To evaluate the nonlinear behavior of the model structures subjected to seismic load, pushover analyses were carried out along the transverse direction by applying incremental lateral load proportional to the fundamental mode of vibration. To define the failure limit state of the model structures, the following two approaches were followed: first, the structure was assumed to have reached a limit state when the inter-story drift reached $1.5 \%$ of the story height as recommended by most seismic design codes such as the ASCE 7 (2010). Second, a structural failure was defined when formation of plastic hinges leaded to failure mechanism. The model structures were assumed to have failed when either of the two limit states occurred.

The base shear versus roof displacement relationship for each model structure is depicted in Fig. 7 where it can be 


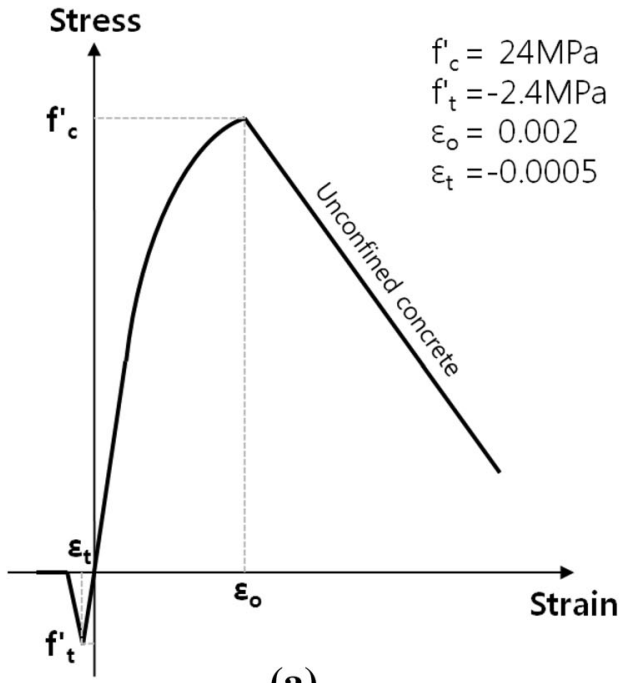

(a)

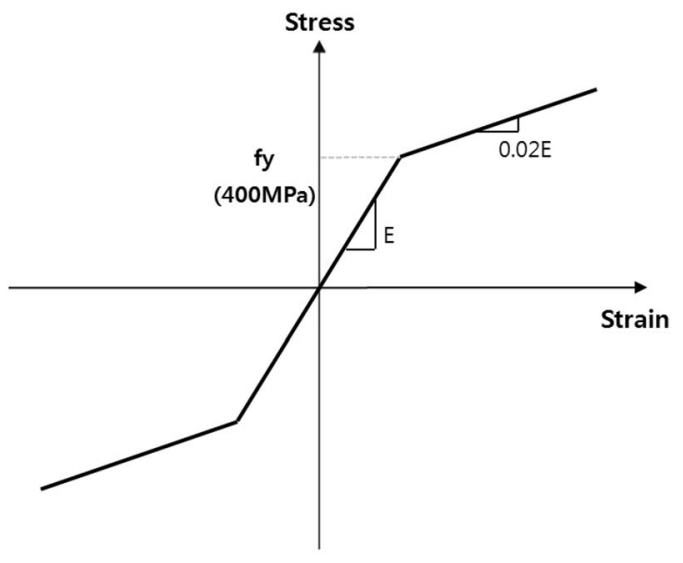

(b)

Fig. 3 Stress-strain relationships of structural materials. a Concrete. b Re-bars.

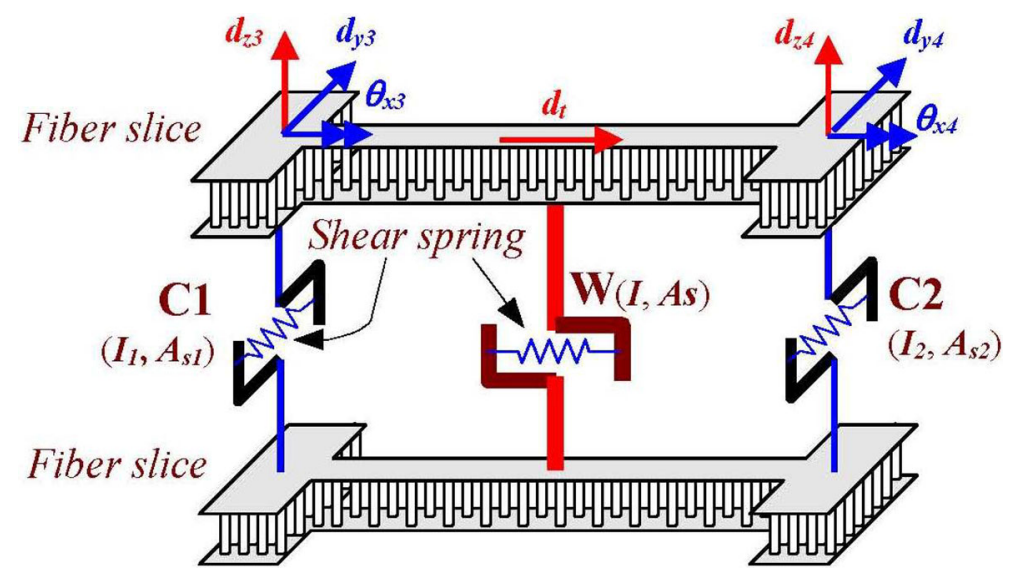

Fig. 4 Fiber model for staggered walls.

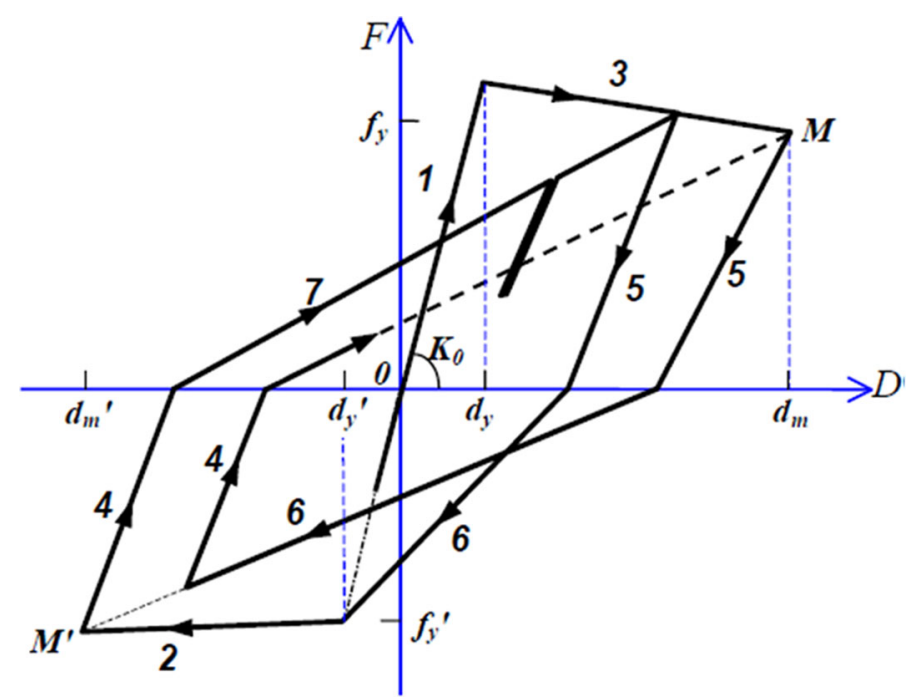

Fig. 5 Modified Clough model for flexural deformation.

observed that the five-story structure with $9 \mathrm{~m}$-long wall designed for medium-level seismic load have highest strength and the 20 five-story structure with $6 \mathrm{~m}$ wall designed for low-level seismic load have lowest strength. The strength decreased as the number of story increased. The structures with $9 \mathrm{~m}$-long staggered walls showed higher strength than those with $6 \mathrm{~m}$ staggered walls. However the maximum displacements were generally larger in the structures with $6 \mathrm{~m}$ walls. The model structures designed with medium level seismic load showed higher strength than the 


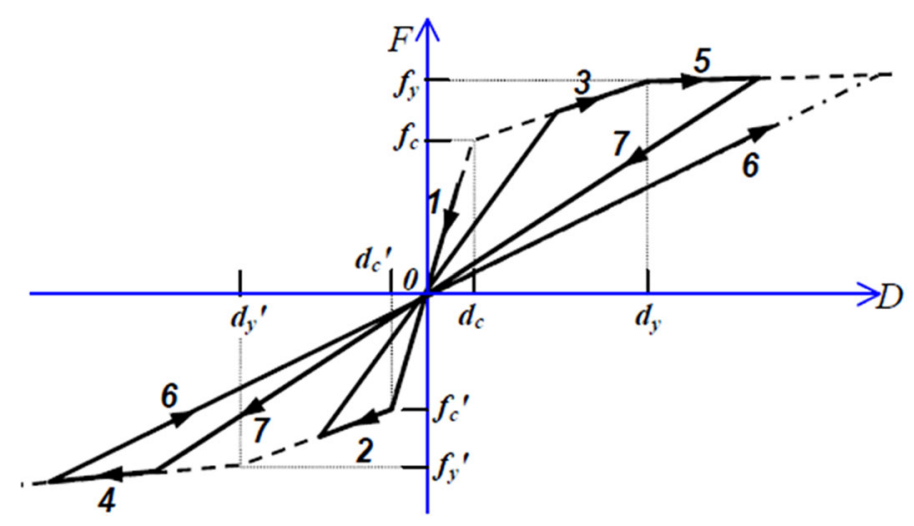

Fig. 6 Origin-oriented model for shear deformation.

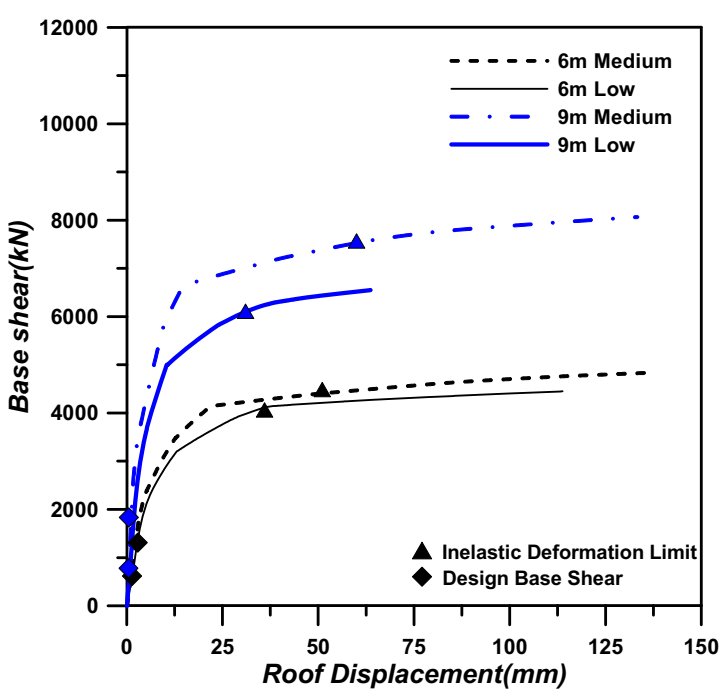

(a)

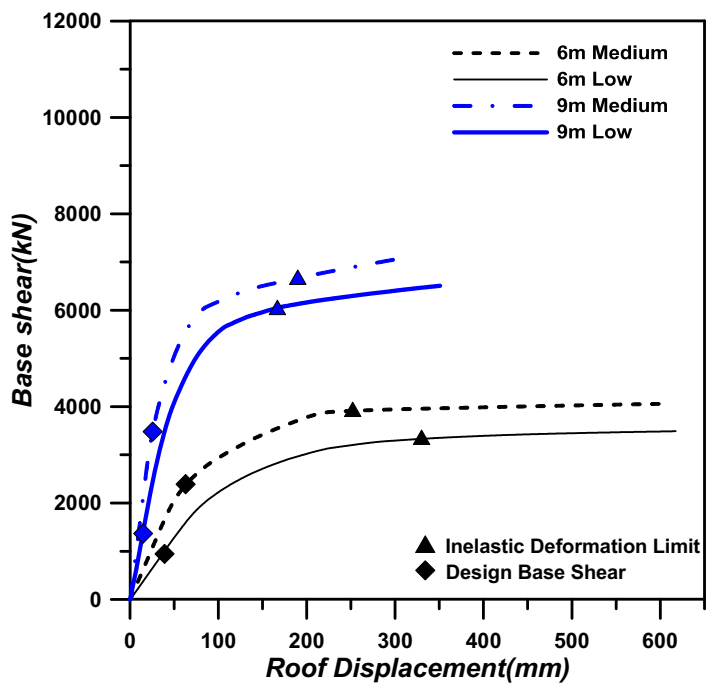

(c)

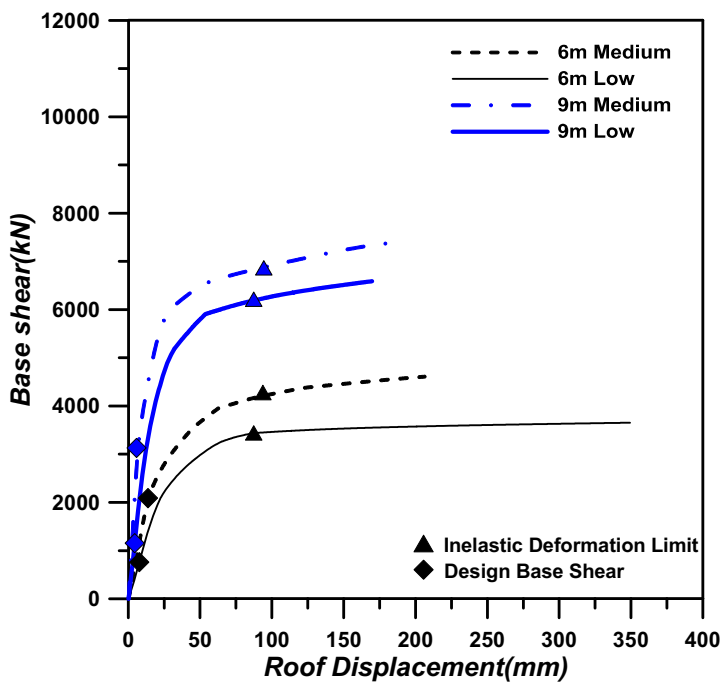

(b)

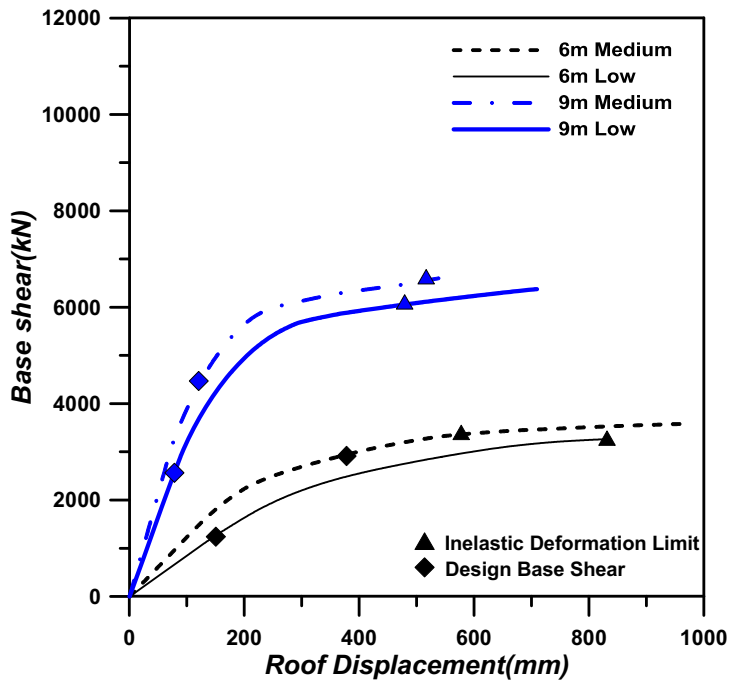

(d)

Fig. 7 Pushover curves of analysis model structures. a 5-story, b 9-story, c 15-story, d 25-story.

structures designed with low level seismic load. It also can be observed that, even though the design base shear increases as the number of story increases, the maximum strength does not increase proportionally to the design base shear. This is due to the fact that as the number of story increases the damage is concentrated in the lower few stories, as can be observed in the plastic hinge formation presented in Fig. 13. This implies that the SWS in its standard form may not be efficient in the medium to highrise buildings. 


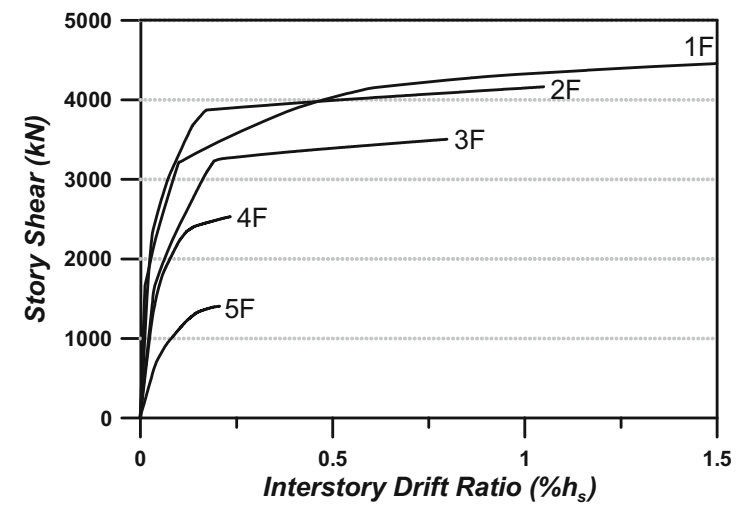

(a)

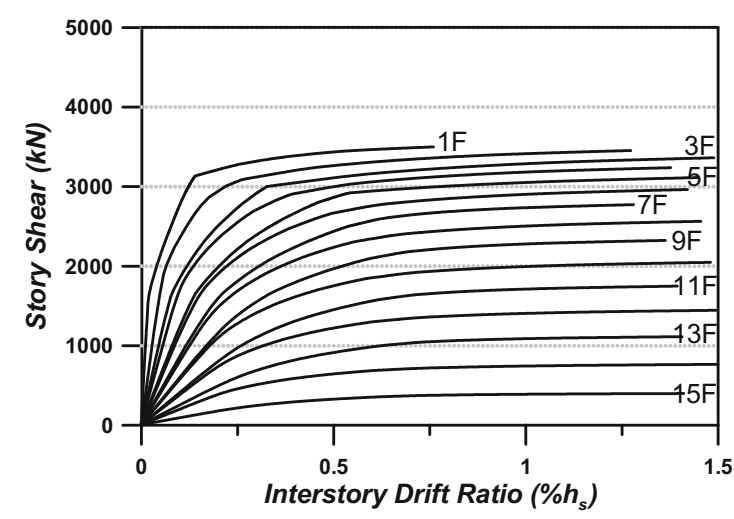

(c)

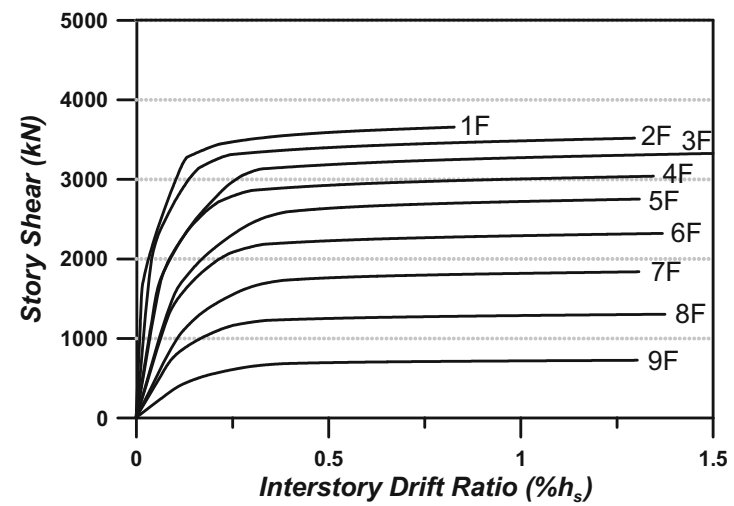

(b)

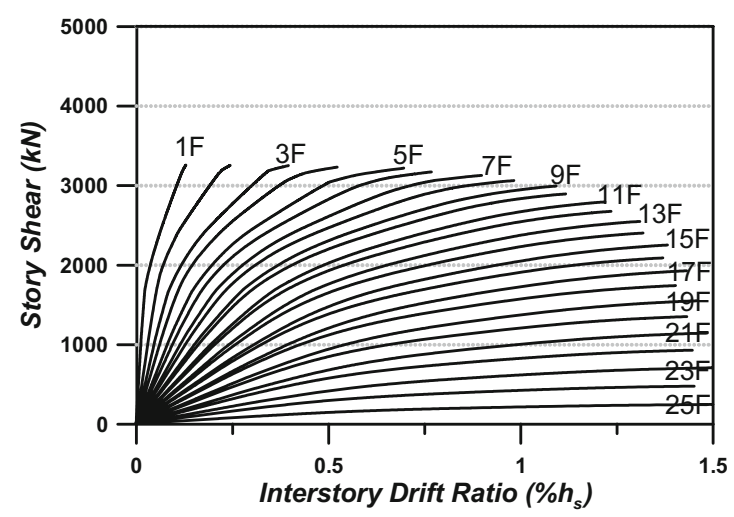

(d)

Fig. 8 Story shear versus inter-story drift curves of the model structures with $6 \mathrm{~m}$-long staggered walls designed for low-level seismic load. a 5-story, b 9-story, c 15-story, d 25-story.

Figures 8, 9, 10 and 11 show the story shear versus interstory drift curves of model structures. It can be noticed that both story stiffness and story strength are larger in lower stories. Compared with the story shear versus inter-story drift curves of higher stories, the curves of lower stories generally show distinct yield points. In the low-rise structures, large deformation is concentrated in the lower few stories. This trend is more noticeable in the structures with $9 \mathrm{~m}$ staggered walls designed for low seismic load. As the building height increases and the wall length decreases, deformation is more uniformly distributed throughout the stories.

Figure 12 shows the inter-story drifts of the model structures obtained from pushover analysis. The pushover analyses were performed until the maximum inter-story drift reached $1.5 \%$ of the story height. It can be observed that the inter-story drifts of the structures with $6 \mathrm{~m}$ wall length are relatively uniformly distributed along the height. It also can be noticed that in the five- and nine-story structures with $6 \mathrm{~m}$ span, large inter-story drifts occurred in the lower stories, whereas the inter-story drifts are more uniformly distributed in the fifteen- and 20 five-story structures. In the structure with $9 \mathrm{~m}$ span length, large inter-story drifts occurred in the lower-stories in all structures. This implies that the staggered wall structures with $9 \mathrm{~m}$ span length behave more like moment frames, whereas the structures with $6 \mathrm{~m}$ span behave more like shear wall structures. It was observed in all model structures that the maximum inter-story drift of $1.5 \%$ of the story height was reached prior to the story collapse mechanism. Figure 13 shows the plastic hinge formation of the model structures with $6 \mathrm{~m}$ walls designed for medium seismic load when the maximum inter-story drift reached $1.5 \%$ of the story height. It was observed that in the low-rise model structures the first story walls yielded first followed by yielding of the first-story columns. In the higher structures plastic hinges formed first at the top and bottom ends of the columns located in the higher stories due to the higher mode effects. However at the ultimate state most plastic hinges were concentrated in the lower story columns as can be observed in the figure. Similar results were also observed in Kim and Han (2013).

For seismic performance evaluation of the model structures with $6 \mathrm{~m}$ staggered walls designed for medium seismic load, incremental dynamic analyses (IDA) were carried out using the El Centro and the Taft earthquakes. Figure 14 shows the response spectra of the Taft and El Centro earthquakes scaled to the design spectra for the low and the medium seismic loads. IDA were carried out with the following procedure: (1) Scale the earthquake records so that the pseudo acceleration $S_{a}$ at the fundamental period of the structure becomes $0.1 \mathrm{~g}$; (2) Carry out nonlinear dynamic analysis and estimate the maximum inter-story drift and base shear of the structure; (3) Increase $S_{a}$ by $0.1 \mathrm{~g}$ and carry out the same analysis procedure. Figure 15 compares the base 


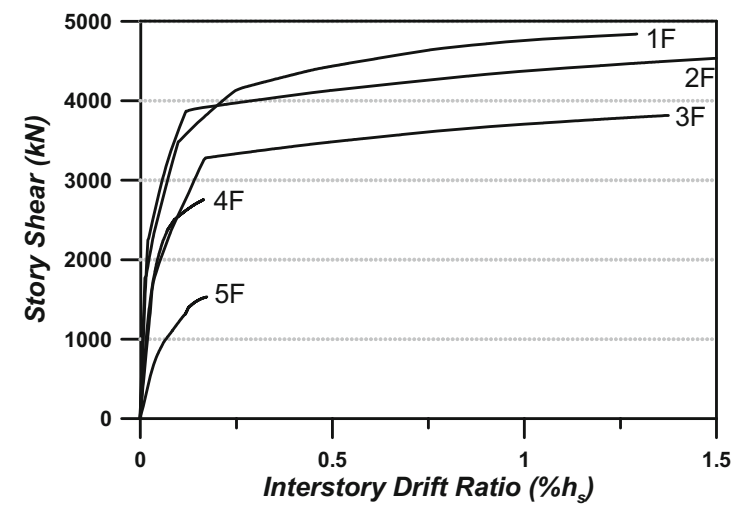

(a)

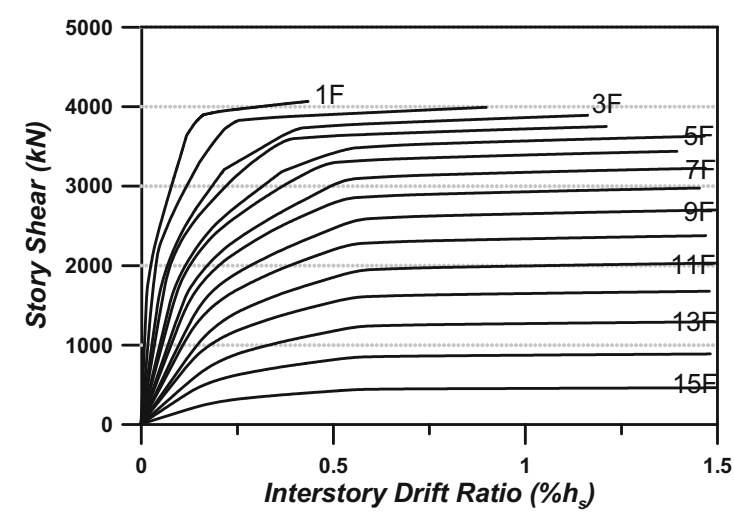

(c)

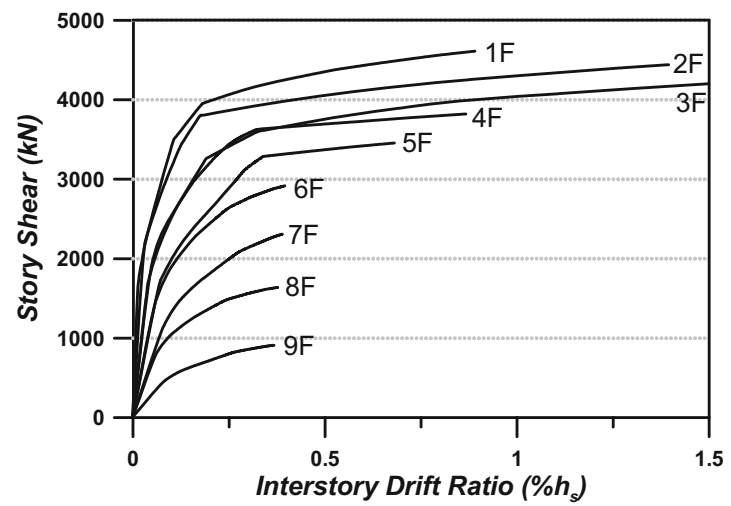

(b)

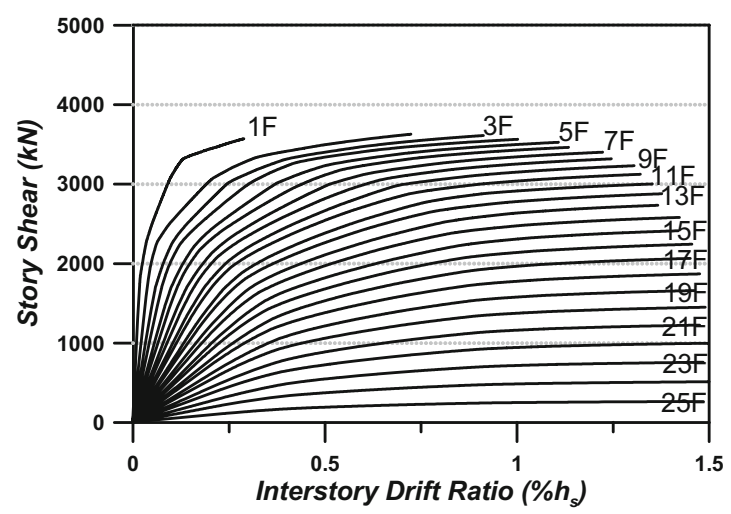

(d)

Fig. 9 Story shear versus inter-story drift curves of the model structures with $6 \mathrm{~m}$-long staggered walls designed for medium-level seismic load. a 5-story, b 9-story, c 15-story, d 25-story.

shear-roof displacement relationships of the model structures obtained by incremental dynamic analyses and nonlinear static pushover analyses. Except for the slight discrepancy in the results of the 15- and 25-story model structures, the base shear-roof displacement curves obtained from IDA and pushover analyses generally coincide well with each other. In the linear elastic deformation stage the two results are almost identical. After yielding slight difference is observed between the two results; however the difference is not significant.

\section{Behavior Factors of the Model Structures}

The ATC-19 (1995) proposed simplified procedure to estimate the response modification factors by the product of the three parameters that profoundly influence the seismic response of structures:

$$
R=R_{o} R_{\mu} R_{\gamma}
$$

where $R_{o}$ is the overstrength factor to account for the observation that the maximum lateral strength of a structure generally exceeds its design strength. Similar procedure was applied to evaluate the seismic design factors for reinforced concrete moment frames (AlHamaydeh et al. 2011), reinforced masonry structures (Shedid et al. 2011), and steel moment resisting frames with buckling restrained braces
(Abdollahzadeh et al. 2012). The FEMA (2000) specified three components of overstrength factors in Table C5.2.7-1: design overstrength, material overstrength, and system overstrength. $R_{\mu}$ is a ductility factor which is a measure of the global nonlinear response of a structure, and $R_{\gamma}$ is a redundancy factor to quantify the improved reliability of seismic framing systems constructed with multiple lines of strength. In this study the redundancy factor was assumed to be 1.0 based on the fact that there are more than four seismic loadresisting frames along the transverse direction. Then the response modification factor is determined as the product of the overstrength factor and the ductility factor. From the base-shear versus roof displacement relationships, the overstrength factor and the ductility factor are obtained as follows (ATC-19 1995):

$$
\begin{gathered}
R_{o}=\frac{V_{y}}{V_{d}} \\
R_{\mu}=\frac{V_{e}}{V_{y}}
\end{gathered}
$$

where $V_{d}$ is the design base shear, $V_{e}$ is the maximum seismic demand for elastic response, and $V_{y}$ is the base shear corresponding to the yield point, which can be obtained from the capacity curves. To find out the yield point, straight lines are drawn on the pushover curve as depicted in Fig. 16 in such a way that the area under the original curve is equal to 


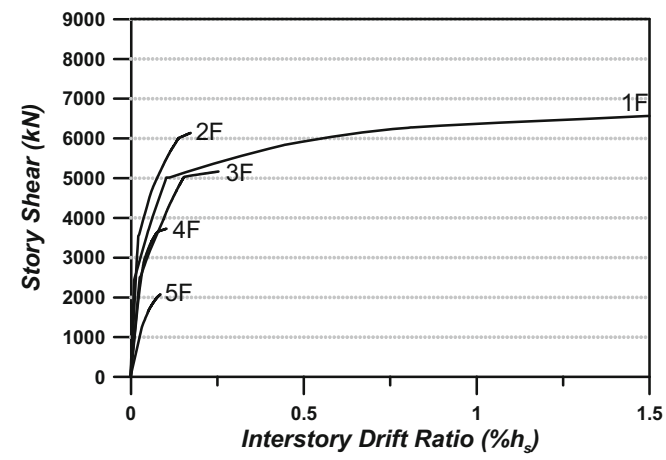

(a)

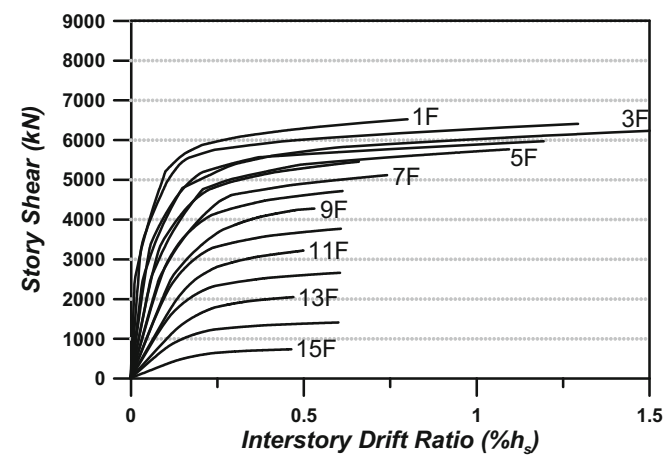

(c)

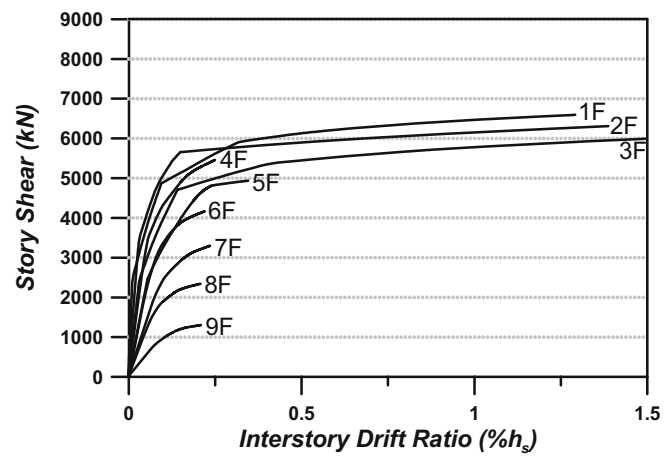

(b)

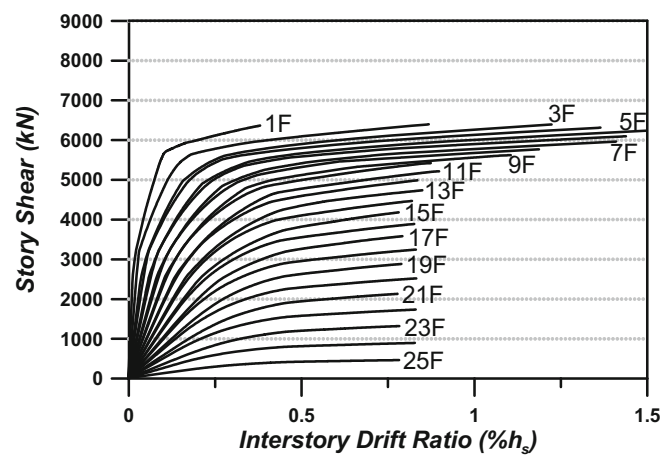

(d)

Fig. 10 Story shear versus inter-story drift curves of the model structures with $9 \mathrm{~m}$-long staggered walls designed for low-level seismic load. a 5-story, b 9-story, c 15-story, d 25-story.

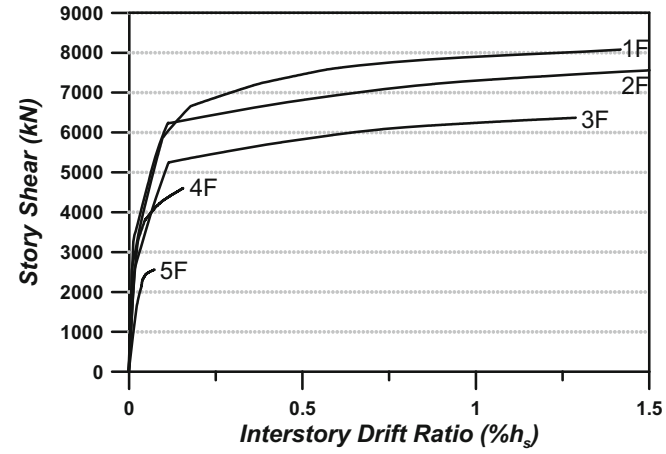

(a)

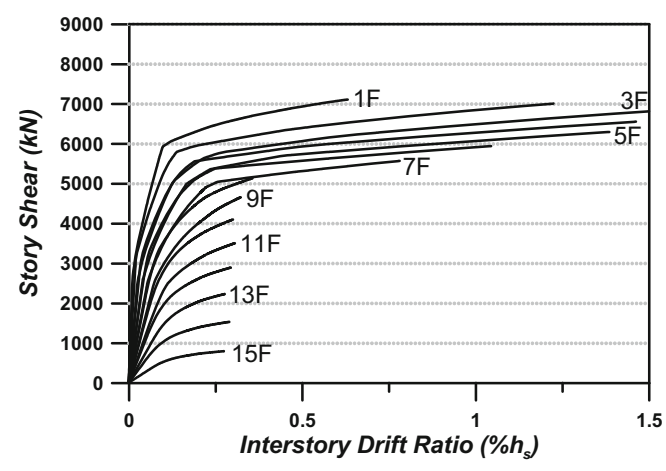

(c)

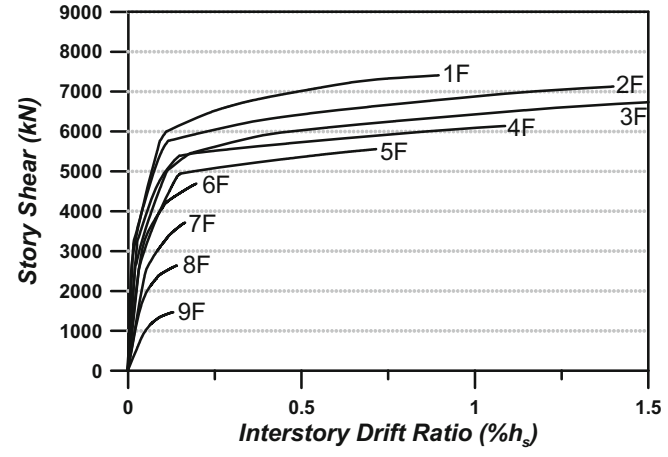

(b)

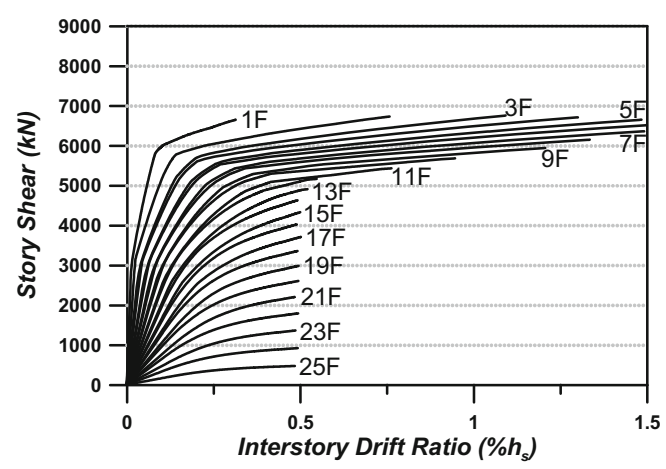

(d)

Fig. 11 Story shear versus inter-story drift curves of the model structures with 9 m-long staggered walls designed for mediumlevel seismic load. a 5 -story, b 9-story, c 15-story, d 25-story. 


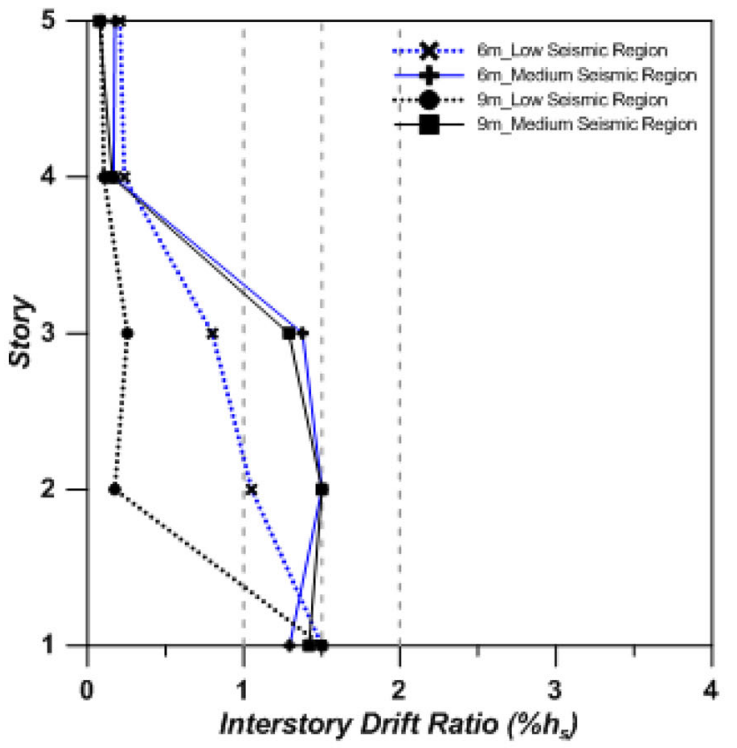

(a)

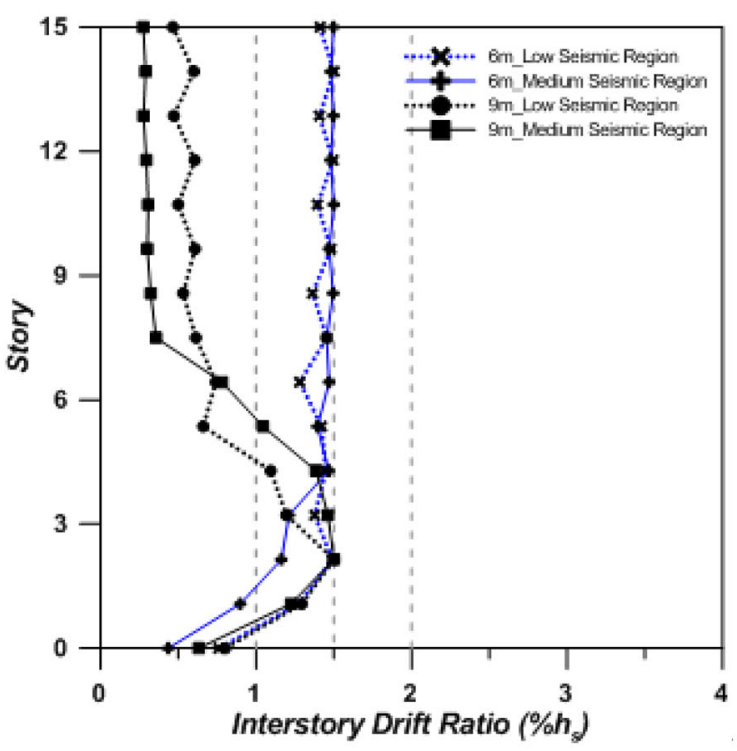

(c)

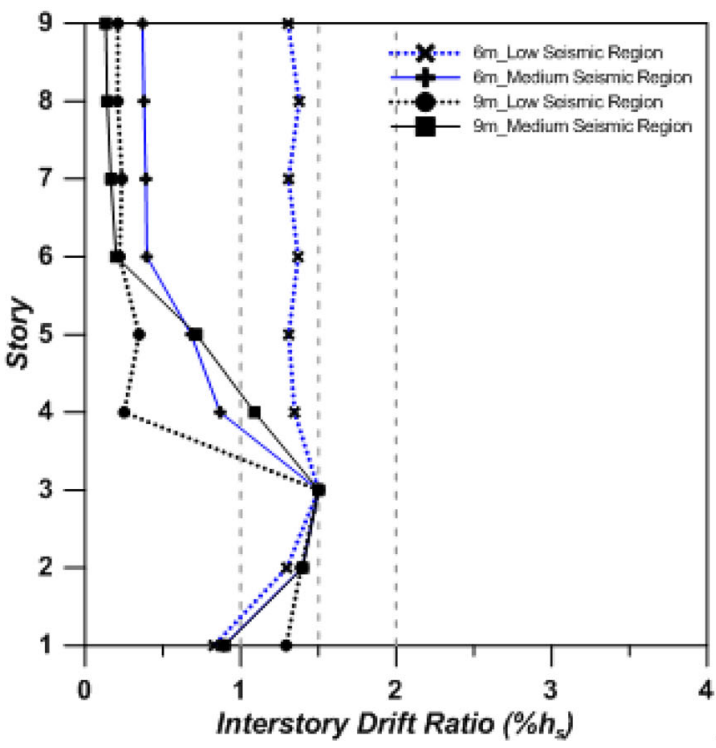

(b)

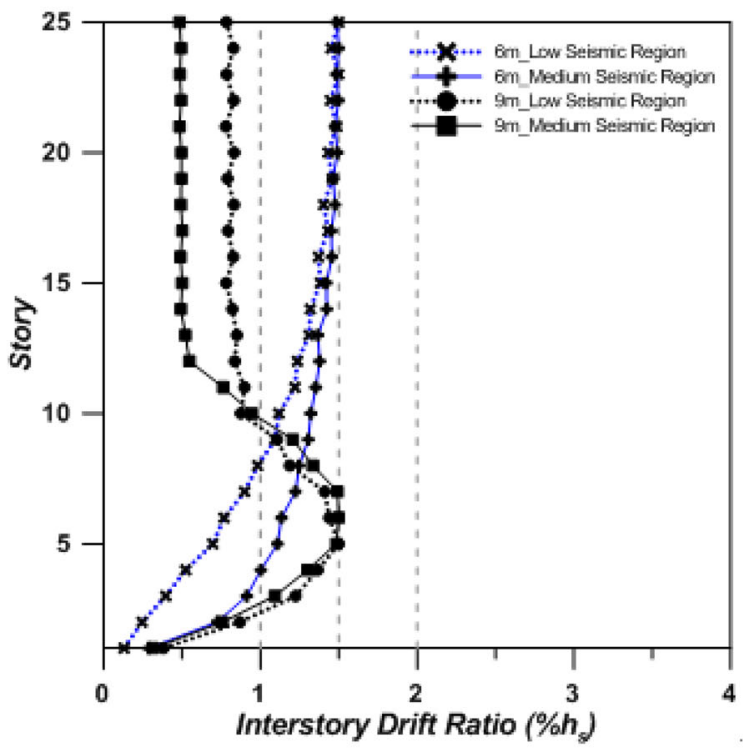

(d)

Fig. 12 Inter-story drifts of model structures. a 5-story, b 9-story, c 15-story, d 25-story.

that of the idealized one as recommended in the FEMA-356 (2000). In this study the ductility factor was obtained using the system ductility ratio $\mu$ as proposed by Newmark and Hall (1982)

$$
\begin{array}{cc}
R_{\mu}=1.0 & (T<0.003 \mathrm{sec}) \\
R_{\mu}=\sqrt{2 \mu-1} & (0.12<T<0.5 \mathrm{sec}) \\
R_{\mu}=\mu & (T>1.0 \mathrm{sec})
\end{array}
$$

where $T$ is the fundamental natural period of the structure and the ductility ratio was obtained by dividing the roof displacement at failure with the displacement at yield. Equation (3) is plotted in Fig. 17.

The overstrength factors of the model structures were computed using Eq. (2a) based on the capacity curves presented in Figs. 5 and 6, and are plotted in Fig. 18. It can be observed that as the height of the structure increases the overstrength factors decrease. The overstrength factors of the structures designed with medium-level seismic load turned out to be smaller than those of the structures designed with low-level seismic load. The structures with $9 \mathrm{~m}$-long staggered walls showed higher overstrength than the structures with 6 m-long walls.

Figure 19 plots the ductility factors of the model structures. No distinct pattern was observed in the distribution of ductility factors depending on the building height and the seismic load levels, and they were relatively uniform regardless of the height of the model structures and the length of the staggered walls with average value of 2.34. This implies that the ratios of the ultimate and the yield displacements are similar in most model structures. It can be noticed that the five-story 


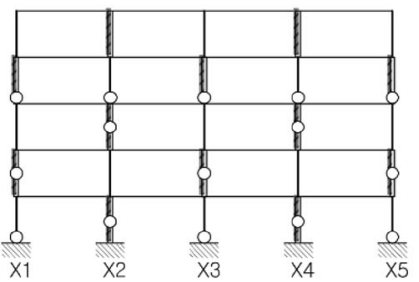

(a)

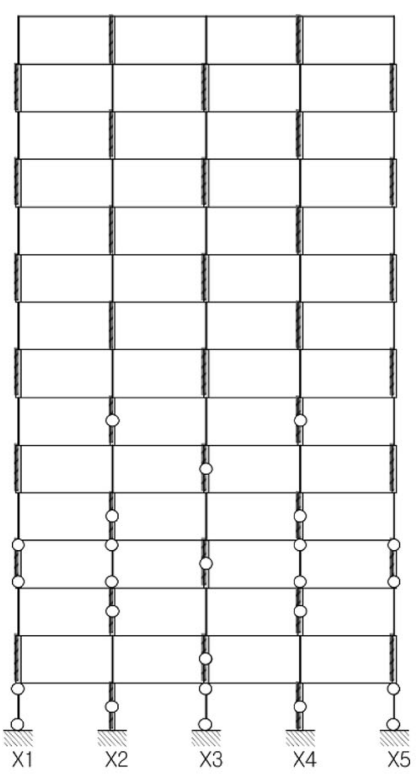

(c)

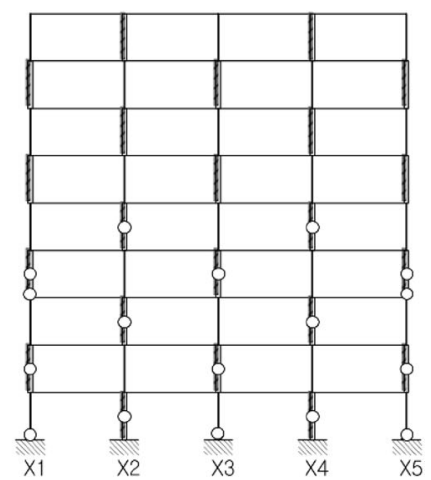

(b)

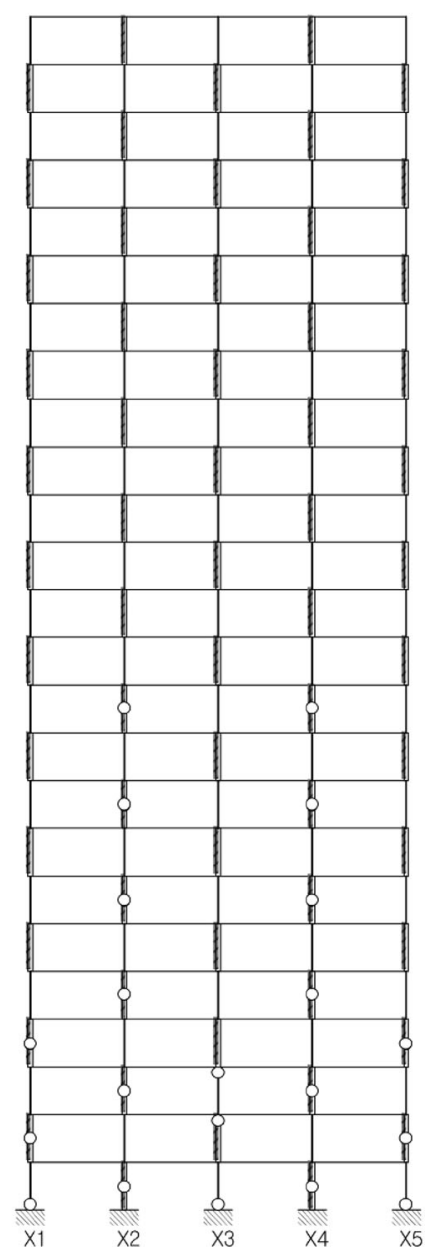

(d)

Fig. 13 Plastic hinge formation of model structures with $6 \mathrm{~m}$-long staggered walls designed for medium-level seismic load. a 5story, b 9-story, c 15-story, d 25-story.

structures designed for medium level earthquake load have slightly larger ductility than the structures designed for low-level seismic load. It was observed from the pushover analysis that the collapse was initiated by yielding of the columns located at the end of the staggered walls. Therefore to reinforce the columns, especially those located in the lower stories, would help to increase the ductility of the SWS structures by preventing or delaying the formation of a story collapse mechanism.

The response modification factors are presented in Fig. 20, which are computed by multiplying the overstrength and the ductility factors. It can be observed that the response modification factors decrease as the height of the structure increases, which conforms to the results of the previous 


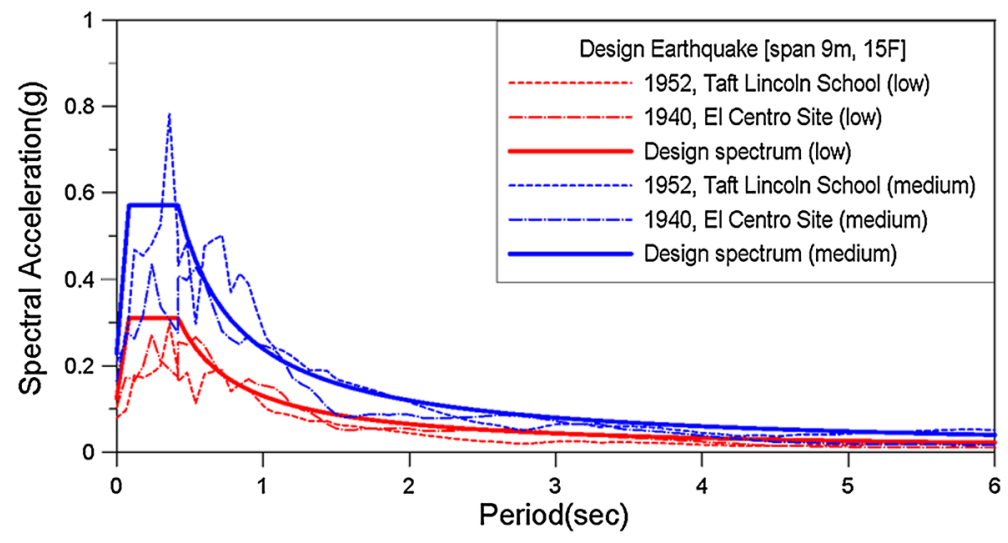

Fig. 14 Response spectra of the Taft and El Centro earthquakes scaled to the design spectra for the low and the medium seismic loads.

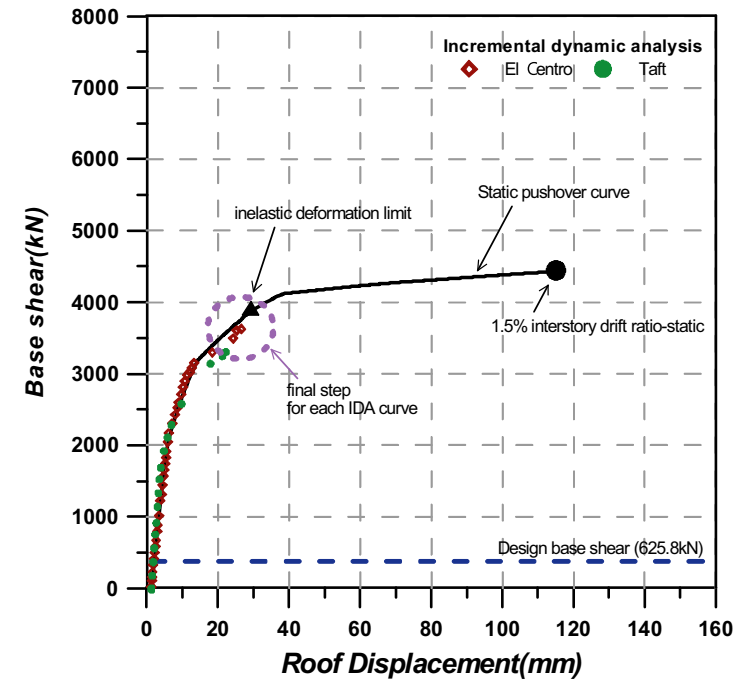

(a)

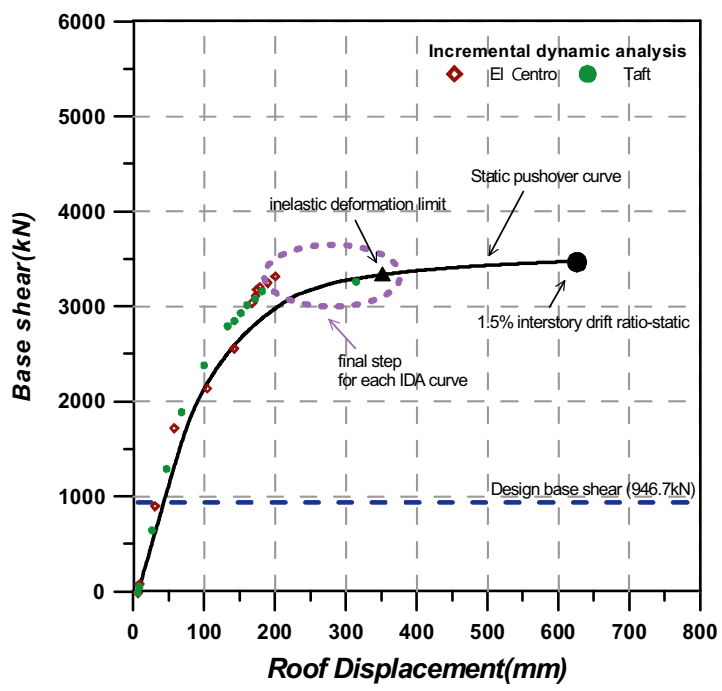

(c)

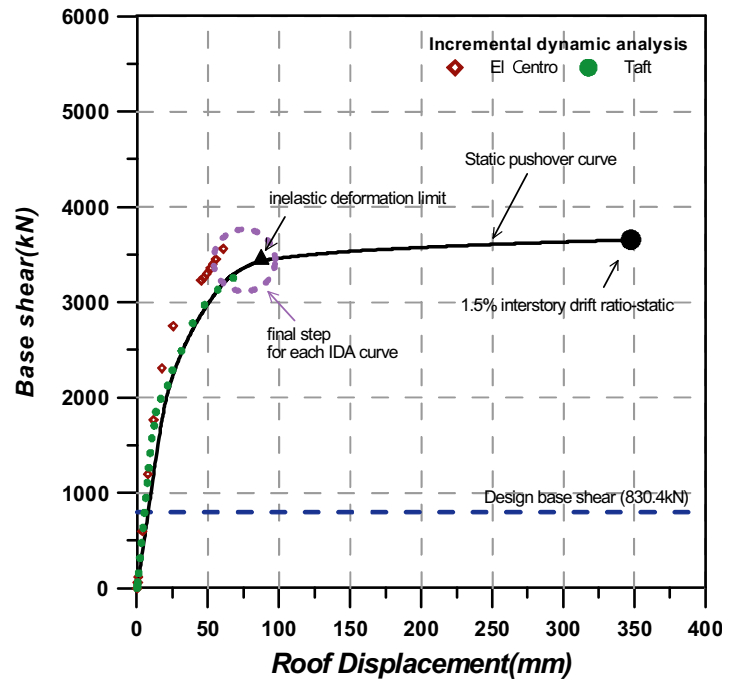

(b)

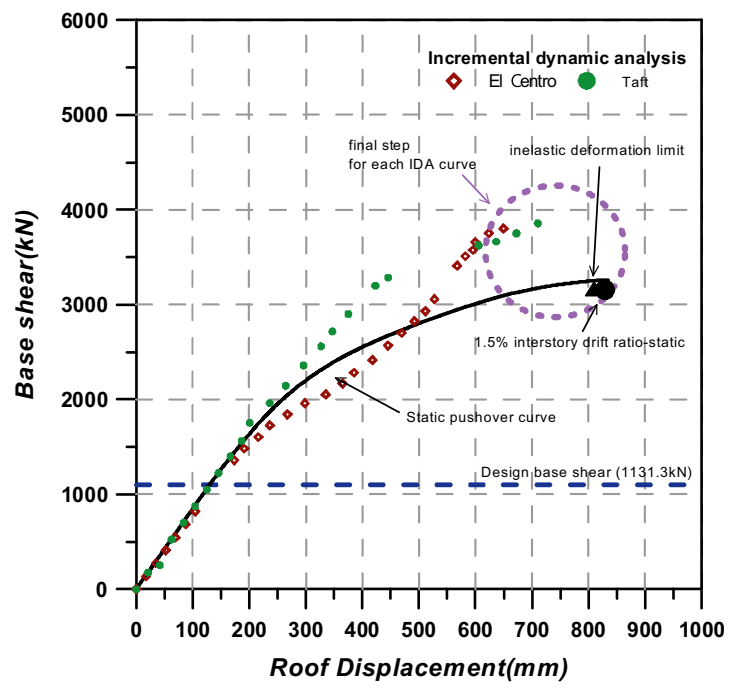

(d)

Fig. 15 Comparison of base shear-roof displacement relationships obtained by pushover analyses and incremental dynamic analyses. a 5-story, b 9-story, c 15-story, d 25-story. 


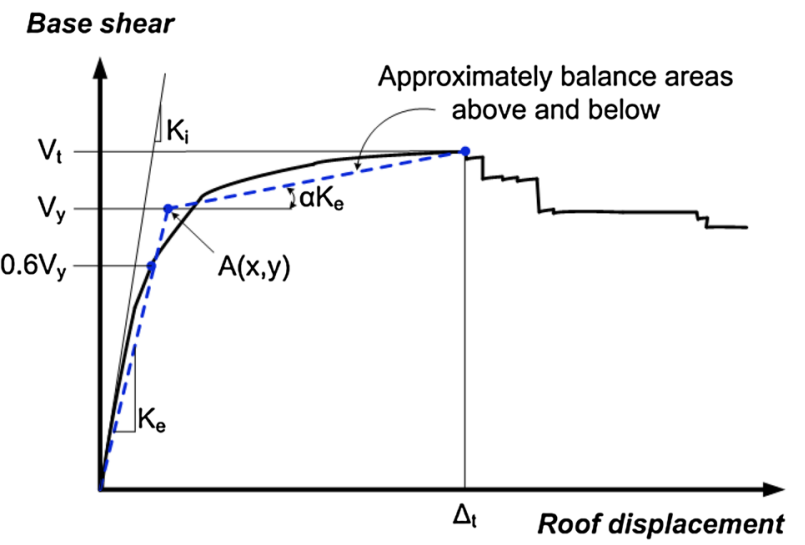

Fig. 16 Bi-linear idealization of a pushover curve.

researches on the structures with staggered trusses (Kim et al. 2007). The mean value for the response modification factors is much larger than 3.0, the code-recommended value for the structures not specified as one of the seismic-load resisting systems. In the 5-story structures, the computed response modification factors are larger than 7.0 ; in the 20 -story structures the factors become as low as 2.0 in the structure with $6 \mathrm{~m}$-long staggered walls designed for medium-level seismic load. However in the most model structures used in this study the computed response modification factors turned out to be larger than 3.0. This implies that the reinforced concrete structures with staggered walls may have enough resistance against design level seismic load. As in the case of the overstrength factors, the structures designed for medium-level earthquake had smaller response modification factors than those of the structures designed with lowlevel seismic load. The structures with $9 \mathrm{~m}$-long staggered walls showed higher response modification factors than the structures with $6 \mathrm{~m}$-long walls except for the 15-story structure designed for low-level seismic load. It can be noticed that the variation of the response modification factors is mainly contributed from the variation of the overstrength factors.

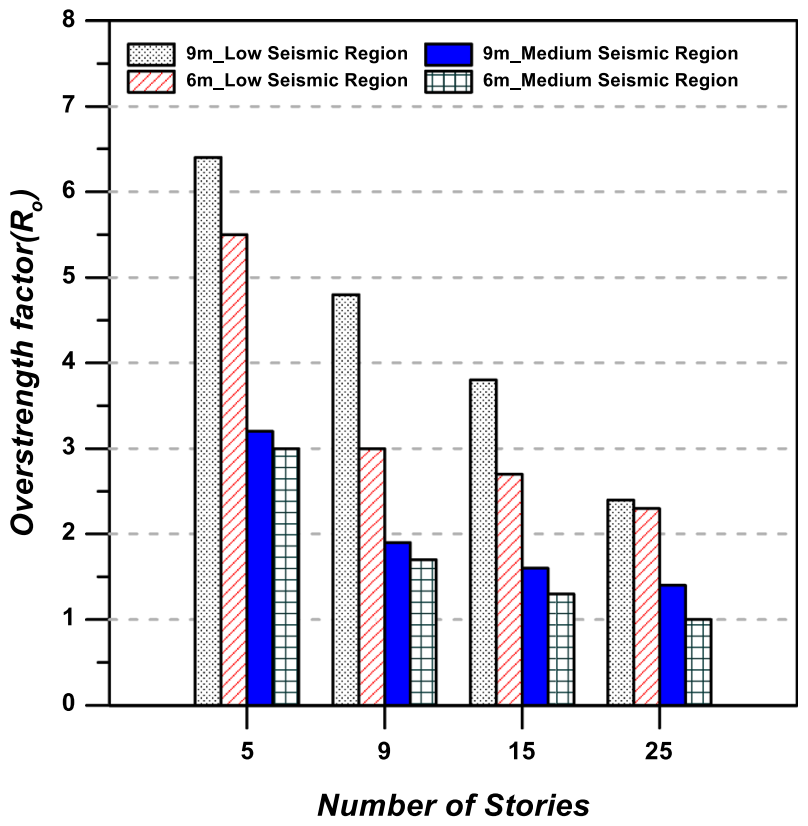

Fig. 18 Overstrength factors of model structures.

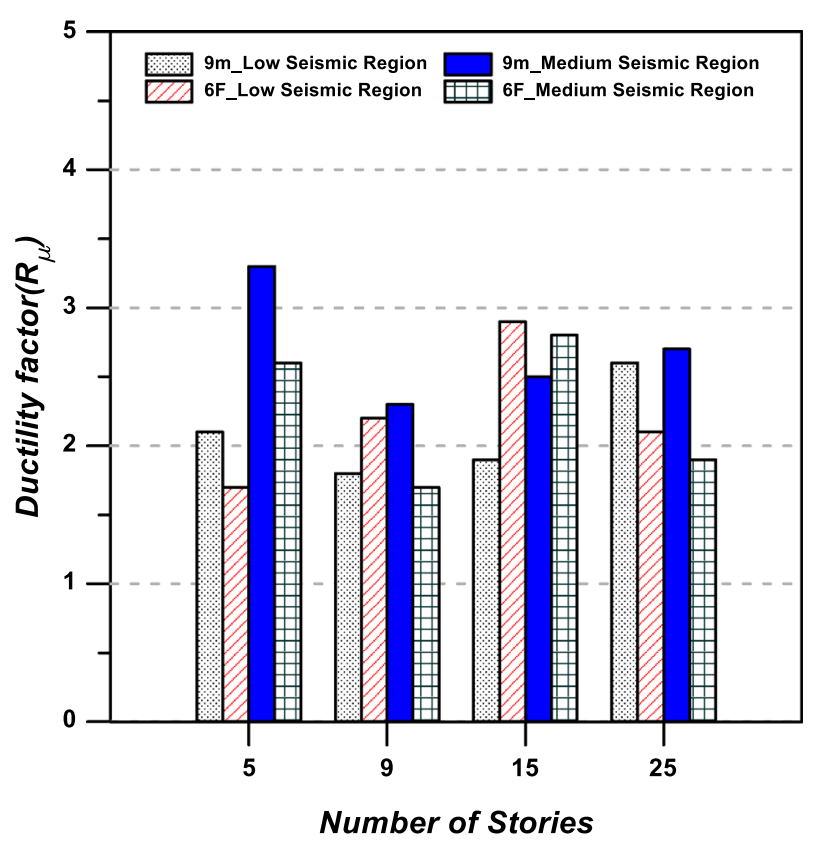

Fig. 19 Ductility factors of model structures.

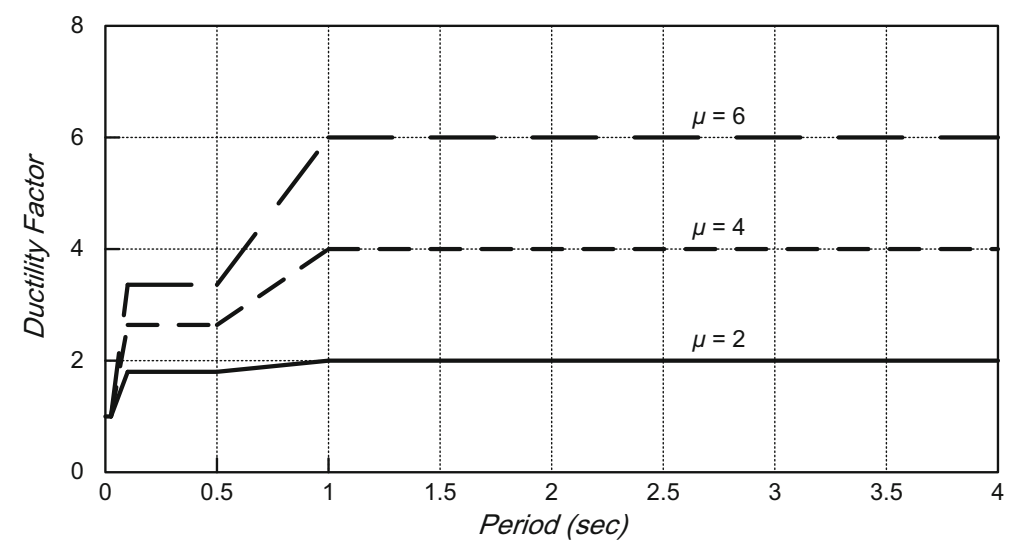

Fig. 17 Relationship between ductility factor and natural period proposed by Newmark and Hall (1982). 


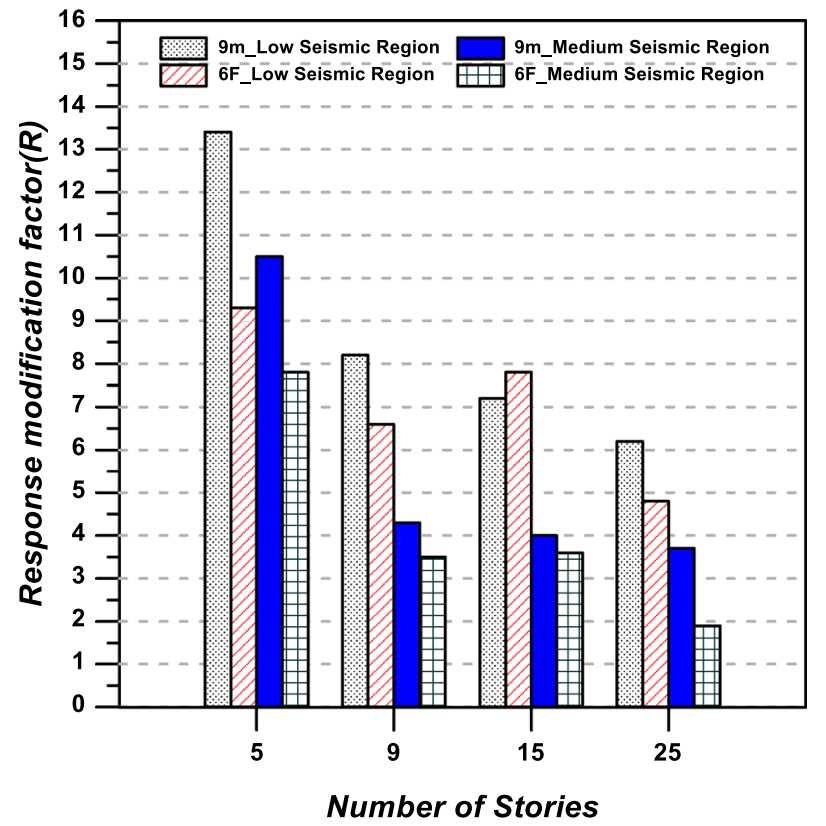

Fig. 20 Response modification factors of model structures.

\section{Conclusions}

One of the main obstacles to be overcome for application of staggered wall systems is to ensure the seismic safety of the systems and to provide valid seismic design coefficients. In this study seismic performance and the behavior factors such as overstrength factors, ductility factors, and the response modification factors of reinforced concrete SWS structures were evaluated. The analysis results showed that the behavior factors obtained by pushover analysis and incremental dynamic analysis turned out to be similar to each other. The overstrength factors of the structures designed with medium-level seismic load turned out to be smaller than those of the structures designed with low-level seismic load. This is due mainly to the fact that the participation of gravity load is more significant in the design of the latter system. The structures with $9 \mathrm{~m}$-long staggered walls showed higher overstrength than the structures with $6 \mathrm{~m}$ long walls. The ductility factors were relatively uniform regardless of the height of the model structures and the length of the staggered walls with average value of 2.34 . The response modification factors obtained by multiplying overstrength factor and ductility factor decreased as the number of stories increased. Except for the structure with $6 \mathrm{~m}$-long staggered walls designed for medium-level seismic load, the response modification factors turned out to be higher than 3.0 which was used for evaluation of design seismic load. The magnitude of the response modification factors were contributed mainly from large overstrength rather than from large deformability. The response modification factors of the structures designed for low-level seismic load were higher than those of the structures designed for higher seismic load. Based on the analysis results, it is concluded that the RC SWS structures generally have adequate strength and ductility capacities to resist design seismic load. As the response modification factor of the model structures analyzed in this study ranged from 3.5 to 8 , the current response modification factor of 3.0 seems to be in the conservative side and a little higher value of 3.5 or 4.0 may be more appropriate value for seismic design of staggered wall structures.

It was also observed that the maximum strength of the model structures did not increase proportionally to the design base shear, even though the design base shear increased as the number of story increased. This is due to the fact that as the number of story increased the damage was concentrated in the lower few stories. Even though no story failure mechanism was observed until maximum inter-story drift of $1.5 \%$ was reached in all model structures, it would be necessary to delay the occurrence of story failure mechanism by reinforcing lower story columns to increase seismic-load resisting capacity of the structures. Also the adoption of seismic joint details specified in the ACI code will help increase the ductility of the system.

Finally it needs to be stated that, as the seismic performance of the staggered wall structures has not been validated by proper tests, further experimental research is still required for accurate evaluation of the seismic load resisting capacity of the staggered wall structures. Also the use of more accurate nonlinear concrete model will help enhance the validity of this study

\section{Acknowledgments}

This research was supported by a Grant (13AUDPB066083-01) from Architecture \& Urban Development Research Program funded by Ministry of Land, Infrastructure and Transport of Korean government.

\section{Open Access}

This article is distributed under the terms of the Creative Commons Attribution 4.0 International License (http://creativecommons.org/licenses/by/4.0/), which permits unrestricted use, distribution, and reproduction in any medium, provided you give appropriate credit to the original author(s) and the source, provide a link to the Creative Commons license, and indicate if changes were made.

\section{References}

Abdollahzadeh, G. H., Banihashemi, M. R., Elkaee, S. \& Esmaeelnia A. M. (2012). Response modification factor of dual moment-resistant frame with buckling restrained brace (BRB). 15th World Congress of Earthquake Engineering, 2012. Portugal: Lisbon.

ACI 318. (2005). Building code requirements for structural concrete and commentary (ACI 318 M-05). Farmington Hills, Michigan: American Concrete Institute. 
AlHamaydeh, M., Abdullah, S., Hamid, A., \& Mustapha, A. (2011). Seismic design factors for RC special moment resisting frames in Dubai, UAE. Earthquake Engineering and Engineering Vibration, 10(4), 495-506.

ASCE 7. (2010). Minimum design loads for buildings and other structures. Reston, VA: American Society of Civil Engineers.

ATC-19. (1995). Structural response modification factors (pp. 5-32). Redwood City, CA: Applied Technology Council.

ATC. (1995). A critical review of current approaches to earthquake-resistant design, ATC-34 (p. 31-6). Redwood City, CA: Applied Technology Council.

Calabrese, A., Almeida, J. P., \& Pinho, R. (2010). Numerical issues in distributed inelasticity modeling of RC frame elements for seismic analysis. Journal of Earthquake Engineering, 14(S1), 38-68.

Clough R. W. \& Johnston S. B. (1966). Effect of stiffness degradation on earthquake ductility requirements. In Proceedings of the Japan Earthquake Engineering Symposium.

FEMA. (2000). Prestandard and commentary for the seismic rehabilitation of buildings, FEMA-356. Washington, D.C.: Federal Emergency Management Agency.

Fintel, A. M. (1968). Staggered transverse wall-beams for multistory concrete buildings - a detailed study. Skokie, IL: Portland Cement Association.

ICC (International Code Council). (2009). International building code. Falls Church, VA: International Code Council.

Kent, D. C., \& Park, R. (1971). Flexural members with confined concrete. ASCE, 97(7), 1969-1990.

Kim, J., \& Han, S. (2013). Sensitivity analysis for seismic response of reinforced concrete staggered wall structures. Magazine of Concrete Research, 65(22), 1048-1059.

Kim, J., \& Jun, Y. (2011). Seismic performance evaluation of partially staggered wall apartment buildings. Magazine of Concrete Research, 63(12), 927-939.

Kim, J., \& Lee, M. (2013). Fundamental period formulas for RC staggered wall buildings. Magazine of Concrete Research, 66, 325-338. Accepted for publication.

Kim, J., Lee, J., \& Kim, Y. (2007). Inelastic behavior of staggered truss systems. The Structural Design of Tall and Special Buildings, 16(1), 85-105.

Lee, J., \& Kim, J. (2013). Seismic performance evaluation of staggered wall structures using FEMA P695 procedure. Magazine of Concrete Research, 65(17), 1023-1033.

Li, K-N. (2004). CANNY:3-dimensional nonlinear static/dynamic structural analysis computer program-user manual. Vancouver, Canada: CANNY Structural Analysis.
Li, Z., \& Hatzigeorgiou, G. D. (2012). Seismic damage analysis of RC structures using fiber beam-column elements. Soil Dynamics and Earthquake Engineering, 32(1), 103-110.

Li, N., Li, Z., \& Xie, L. (2013). A fiber-section model based Timoshenko beam element using shear-bending interdependent shape function. Earthquake Engineering and Engineering Vibration, 12(3), 421-432.

Mee, A. L. (1975). Wall-beam frames under static lateral load. ASCE, 101(2), 377-395.

Newmark, N. M., \& Hall, W. J. (1982). Earthquake spectra and design, EERI, monograph series. Oakland, CA: Earthquake Engineering Research Institute.

Orakcal, K., Wallace, J. W., \& Conte, J. P. (2004). Nonlinear modeling and analysis of slender reinforced concrete walls. ACI Structural Journal, 101(5), 688-698.

Sfakianakis, M. G. (2002). Biaxial bending with axial force of reinforced, composite and repaired concrete sections of arbitrary shape by fiber model and computer graphics. Advances in Engineering Software, 33(4), 227-242.

Shedid, M., El-Dakhakhni, W., \& Drysdale, R. (2011). Seismic response modification factors for reinforced masonry structural walls. Journal of Performance of Constructed Facilities, 25(2), 74-86.

Skalomenos, K. A., Hatzigeorgiou, G. D., \& Beskos, D. E. (2015). Seismic behavior of composite steel/concrete MRFs: Deformation assessment and behavior factors. Bulletin of Earthquake Engineering, 13(12), 3871-3896.

Tomaževič, M., \& Weiss, P. (2010). Displacement capacity of masonry buildings as a basis for the assessment of behavior factor: An experimental study. Bulletin of Earthquake Engineering, 8(6), 1267-1294.

Vamvatsikos, D., \& Cornell, C. A. (2001). Incremental dynamic analysis. Earthquake Engineering and Structural Dynamics, 31, 491-514.

Wallace, J. W. (2012). Behavior, design, and modeling of structural walls and coupling beams-lessons from recent laboratory tests and earthquakes. International Journal of Concrete Structures and Materials, 6(1), 3-18.

Wu, J., \& Hanson, R. D. (1989). Study of inelastic spectra with high damping. Journal of the Structural Engineering, ASCE, 115(6), 1412-1431.

Zou, X., He, Y., \& Xu, L. (2009). Experimental study and numerical analyses on seismic behaviors of staggered truss system under low cyclic loads. Thin-walled Structures, 47(11), 1343-1353. 